\title{
Thickness Measurement Methods for Physical Vapor Deposited Aluminum Coatings in Packaging Applications: A Review
}

\author{
Martina Lindner ${ }^{1, *}$ and Markus Schmid ${ }^{1,2}$ \\ 1 Fraunhofer-Institute for Process Engineering and Packaging IVV, Giggenhauser Strasse 35, \\ Freising 85354, Germany; markus.schmid@ivv.fraunhofer.de \\ 2 Chair for Food Packaging Technology, Technische Universität München, Weihenstephaner Steig 22, \\ Freising 85354, Germany \\ * Correspondence: martina.lindner@ivv.fraunhofer.de; Tel.: +49-8161-491-536
}

Academic Editor: Massimo Innocenti

Received: 14 November 2016; Accepted: 27 December 2016; Published: 14 January 2017

\begin{abstract}
The production of barrier packaging materials, e.g., for food, by physical vapor deposition (PVD) of inorganic coatings such as aluminum on polymer substrates is an established and well understood functionalization technique today. In order to achieve a sufficient barrier against gases, a coating thickness of approximately $40 \mathrm{~nm}$ aluminum is necessary. This review provides a holistic overview of relevant methods commonly used in the packaging industry as well as in packaging research for determining the aluminum coating thickness. The theoretical background, explanation of methods, analysis and effects on measured values, limitations, and resolutions are provided. In industrial applications, quartz micro balances (QCM) and optical density (OD) are commonly used for monitoring thickness homogeneity. Additionally, AFM (atomic force microscopy), electrical conductivity, eddy current measurement, interference, and mass spectrometry (ICP-MS) are presented as more packaging research related methods. This work aims to be used as a guiding handbook regarding the thickness measurement of aluminum coatings for packaging technologists working in the field of metallization.
\end{abstract}

Keywords: PVD; aluminum; quartz micro balance; optical density; AFM; electrical conductivity; eddy current; interference; ICP-MS; metal coating; nano-scale coatings

\section{Introduction}

As early as 1994, researchers were looking for the absolute minimum of material usage for disposable packaging, pursuing the need for environmental protection. Additionally, mono materials are preferred due to easier recyclability [1]. However, pure polymeric materials often fail to fulfill the barrier requirements needed to sufficiently protect packed goods, e.g., food against light, moisture, oxygen, and other gases. In contrast to that, aluminum foil with a thickness of about 6 to $40 \mu \mathrm{m}$ has extremely high barrier properties. Therefore it is predominantly used for the packaging of highly sensitive pharmaceutical products in flexible packaging or blister packs [2,3]. Yet, aluminum has a rather negative environmental impact, which is why we must strive to further reduce its amount [4]. In order to maintain the high barrier properties of aluminum while simultaneously minimizing material usage, nanometer-thin aluminum coatings are applied on polymers via PVD (vacuum evaporation). In this process, aluminum is heated until it evaporates in a vacuum chamber. The polymer substrate is moved across the aluminum gas cloud so that the metal condenses on the polymer surface. In this way, thicknesses of only a few nanometers can be realized. However, in order to reach suitable barrier properties, an approximate thickness of $40 \mathrm{~nm}$ of aluminum is commonly necessary. Apart from pure 
aluminum, aluminum oxide and silicon oxide are common inorganic coating materials (ceramics). In the following review, we refer to aluminum only. The aluminum coating will be referred to as aluminum or coating. When writing about a single atomistic or molecular layer in the aluminum coating, this is referred to as a layer. The substrate polymer is named a substrate or polymer.

\subsection{Deposition Techniques in Packaging Applications}

In general, according to Seshan [5], all deposition techniques can be subdivided into evaporative methods (such as vacuum evaporation), glow-discharge processes combined with either sputtering or plasma processes, gas-phase chemical processes with either chemical vapor deposition or thermal forming processes, and liquid phase chemical techniques combined with either electro processes or mechanical techniques. Thin film application techniques are widely used in industries like microelectronics, photovoltaic devices, and optics. Apart from that, especially vacuum evaporation is used in the packaging industry. However, other methods find their way into the packaging market, such as CVD (chemical vapor deposition), PECVD (plasma-enhanced chemical vapor deposition), ALD (atomic layer deposition), magnetron sputtering and sol-gel coating. Apart from financial and production speed considerations, the decisive factor for choosing one of the methods will be the required characteristics of the coating. The most important task of the coating in the packaging industry is to achieve a suitable barrier against gases. Thus, the coating must be pure and not contain cracks or pores [5]. In the following, vacuum deposition and other coating methods that appear in the packaging industry are described.

During vacuum deposition, commonly only one inorganic material can be deposited. This happens by heating the coating material and the subsequent condensation on the substrate surface. However, if alloys are used, the heating of the target material might lead to a disintegration of the compound. Moreover, undercuts and roughness are difficult to coat. Furthermore, the process requires high-performance cooling and vacuum systems. The vacuum deposition process has the advantage that due to the vacuum the energy to melt the material is reduced, and furthermore, the incorporation of gaseous atoms into the coating is drastically reduced. The deposition rate is highly dependent on the gas pressure in the chamber. The flux distribution can be altered by the source geometry. In comparison to other methods, high deposition rates and extremely pure coatings can be obtained [6].

Sputtering is a process sometimes used in packaging applications, in which atoms from the target are attacked by accelerated ions, which transfer their momentum to the targeted atoms. Thus the targeted atoms are knocked out from the bulk, leave it in a cosine distribution, and then hit the substrate surface and adhere there. The magnetron sputtering technique has the advantage, that secondary electrons generated in the target are trapped so that they cannot hit the substrate surface. Sputtering has a high amount of materials usable for deposition and typically the coating has the same composition as the target material. However, if reactive gases are present in the chamber, they can react with the target and alter the composition. Moreover, the particles have a higher kinetic energy compared to thermally vaporized atoms. It is possible that temperature-sensitive substrates can be coated without excessive temperature impact [6].

In contrast to that, CVD offers the opportunity to introduce precursors into the process chamber, which then react with the metal to form, e.g., metal oxides, nitrides, carbides, borides and others. However, in this process, volatile and partially toxic gases may be produced, which have to be handled separately. At the same time, powerful vacuum pumps are not necessary like in vacuum deposition. As the impacting molecules or atoms have a high kinetic energy, this process might lead to an increase in the substrate temperature. Moreover, the interaction with precursor atoms may lead to a scattering of the evaporated atoms. This in turn can lead to a roughening of the surface, the penetration of atoms or molecules into the material, pinholes and chemical reactions with the rest gases. However, the achieved thicknesses can be up to centimeter scales. As the coating is not limited to line-of-sight areas, the process has the advantage that three dimensional structures, voids, and peaks can also be covered evenly [7]. 
ALD is a layer-by-layer process in which only one monomolecular layer is applied in each production cycle. It is based on alternate pulsing of the precursor gases onto the substrate surface, followed by the chemisorption or surface reaction [8]. The advantage is that the produced layers are perfectly dense and free of pinholes. Therefore, they offer extremely low gas permeabilities. Moreover, temperature and pressure conditions are less intense than in vacuum deposition [9]. Although lately a continuous operation mode was developed, the production speed is rather low and therefore costly.

One example for liquid phase chemical techniques in packaging applications is Ormocer $^{\circledR}$, i.e., organically modified ceramics [10]. Those are applied via a sol-gel process in order to achieve a nanometer thin coating [11,12]. The very basic form of a sol-gel process is the draining and evaporation of the solvent, followed by condensation reactions [13]. This coating leads to smoothening of the surface of polymers. Like this, the negative impact of surface inhomogeneities on barrier performance can be reduced [14]. The advantage in comparison to other processes is the lower amount of required equipment and lower costs. Moreover similar to CVD it provides the possibility to tailor the microstructure of the coating [13].

\subsection{Application of Aluminum via Vacuum Evaporation and Layer Growth}

Physical vapor deposition is not only used for packaging materials, but also e.g., for capacitor films, holographic coatings, transparent conducting oxides, energy conservation windows, solar cells and absorbers, flexible circuits, or thin film batteries [15]. The basic construction for a vacuum evaporation deposition chamber is illustrated in Figure 1. The chamber is divided into two parts, where chamber (A) includes the unwinding $(C)$ and rewinding $(D)$ of the substrate web and holds a low pressure of about $1 \times 10^{-3}$ mbar. The lower part (B) is set under a vacuum of about $1 \times 10^{-5} \mathrm{mbar}$. There are lots of data available about aluminum vapor pressure curves, onset, offset and melting temperature as values change a lot depending on the exact metal composition [16]. However, it can be said that the vacuum reduces the evaporation temperature of aluminum from approximately $2742{ }^{\circ} \mathrm{C}$ at $1013 \mathrm{mbar}$ to $813^{\circ} \mathrm{C}$ at $1 \times 10^{-5}$ mbar $[17,18]$. Moreover the vacuum avoids the scattering of aluminum atoms and their reaction with other gas atoms or molecules (e.g., with oxygen to aluminum oxide). The chilled process roll (I) together with the conductance rolls (E) separate the chamber into (A) and (B), leaving a small opening for the substrate to pass from one zone to the other. The process roll (I) is positioned above the evaporator (F). Two main principles are available for evaporation. The aluminum could either be fed as a wire onto a resistance heated boat, from where it evaporates. Otherwise the aluminum could be fed as granulate in a target and then be heated via an electron beam. In each case the aluminum evaporates and condenses on the surface of the substrate web, which is moved across the process roll (I). The thickness of the aluminum can be adjusted by the web speed or the evaporation rate. The evaporation rate is regulated via the energy input in the evaporator in combination and/or the speed of aluminum feed. The thickness is commonly monitored either by a quartz micro balance (QMB) right at the place of evaporation $(G)$ or by the measurement of optical density $(H)$ before rewinding [15].

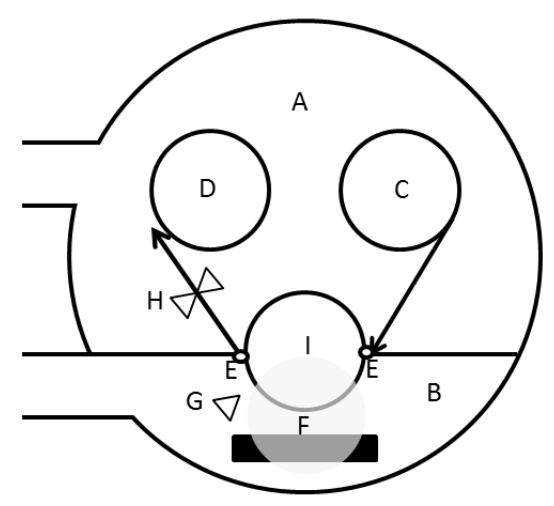

Figure 1. Basic construction of a vacuum deposition chamber (adapted from [1]). 
The growing of condensed atoms to a closed coating and the developing micro structure are dependent on various parameters. The kind of substrate as well as its orientation, evaporation temperature and rate play an important role. Coating thickness, angle of deposition and the energy of condensed atoms or molecules also affect the material structure [19]. Apart from that, the substrate has a major effect on the formation of the coating. In case dust is present on the polymer surface, these particles might be coated with aluminum but then fall off after deposition. In this case, the particle leaves behind a non-coated pinhole, which reduces the gas barrier. One other issue is the substrate roughness. According to [15] and others, valleys in the surface will lead to preferential nucleation and epitaxy as these valleys are energetically favorable for aluminum atoms. Consequently, layer growth is not evenly distributed but rather inhomogeneous. One technique to overcome this problem is the biaxial orientation of polymeric substrates, which leads to the reduction of surface roughness due to the stretching and smoothening of polymeric chains for PET [20]. Generally it is assumed that by stretching the polymer chains align, so that the crystallinity of the material increases and the surface is smoothened [21]. Conversely, a roughening effect due to stretching was reported in [22]. The negative effect of substrate roughness on the gas barrier of inorganic coatings is described in [23,24]. Moreover, the attachment of atoms on the polymer surface depends on the surface tension of the substrate. Surface tension can be increased by plasma treatment, by which e.g., carbonyl, carboxyl, hydroxyl, peroxide, and other groups are introduced onto the polymer surface. There is a tendency that with higher surface tension, more atoms attach on the surface and thus increase the barrier [24]. Additionally, it was reported that plasma treatments can simultaneously alter the surface geometry, as low weight molecules migrate to the charged areas on the surface and consequently built peaks [25].

Layer growth starts with the first nuclei of condensed atoms, which define the subsequent layer structure. The arriving atoms can either deflect from the substrate or lose enough kinetic energy that they are loosely bound as adatoms on the surface. Those adatoms predominantly bind to existing material clusters or to other energetically favorable places. Those could be steps, edges or cavities in the surface topography. If the residual energy is high enough, the atoms further diffuse on the substrate surface. Like this, single adatoms can form stable or metal stable clusters $[26,27]$.

Generally, three models are described, which cover a variety of possible interactions between substrate and adatoms of which model in Figure $2 a, c$ are the two extremes and Figure $2 b$ is a combination of both [26-29]. In the model of Frank van der Merwe (Figure 2a), the cohesion between the adatoms is weaker than the binding to the substrate. Then, a monolayer grows, which is first fully closed, before the next layers start to grow. In comparison to that, the Stranski-Krastanov model (Figure 2b) introduces the idea that first single layers grow like in (Figure 2a), on which islands then start to appear. The Volmer-Weber model (Figure 2c) goes to the other extreme and assumes that the interactions between adatoms are stronger then the interaction with the substrate. After the nucleation of small clusters, these grow to small three-dimensional islands. Only at high layer thicknesses can closed coating be achieved [29-32].

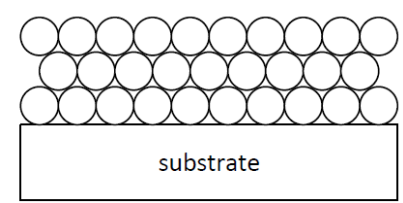

(a)

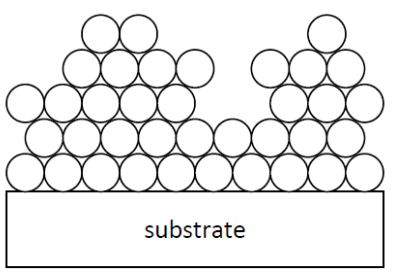

(b)

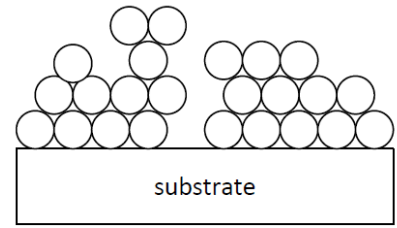

(c)

Figure 2. Models for layer growth: Frank van der Merwe (a); Stranski-Krastanov (b); Volmer-Weber (c) (adapted from $[1,15]$ ). 


\subsection{Pores and Defects}

Normally, metals have a crystalline structure, i.e., a strictly periodical arrangement of atoms. Therefore, Bravais [33] introduced the concept of a space lattice, which equals a three-dimensional mathematical point pattern. Herein, each point can be imagined as the center of an atom. Metallic elements mostly crystallize in three lattice types [34]: cubic body centered, cubic face centered, and hexagonal. Aluminum typically crystallizes in a cubic face centered manner [35]. However, crystalline structures are never free of defects. Defects are subdivided into (i) blank spaces and interstitials; (ii) displacements; (iii) grain and phase limits [34,36] and can affect physical properties like barrier towards gases, electrical conductivity, and optical density.

Apart from the defects due to the lattice, additional macroscopic defects might appear due to contamination with dust prior to the deposition process. These dust particles might stick on the substrate surface, are then covered with aluminum and fall off the substrate afterwards as they are only loosely bound. In such a case, this leaves behind a defect in the coating. Additionally some films contain so-called anti-block particles on one side of the film. When the material is winded, the backside of the film touches the front side of the film. Consequently, the anti-block particles can injure the inorganic nano-scale aluminum coating [37].

\subsection{Formation of Aluminum Oxide}

Aluminum is a reactive metal that easily oxidizes when it is taken out of the vacuum chamber and set under atmospheric conditions. Hence it builds up a stable oxide layer that has an amorphous structure and protects the underlying metal from further corrosion and oxidation. Then the oxide layer is hydrated to aluminum oxide hydroxide or aluminum hydroxide [38,39]. The oxide layer has a thickness of 3 to $10 \mathrm{~nm}$ [39-42]. In [42] it was observed, that the oxide layer grows not only on the outer surface but also between the aluminum and the substrate web.

\subsection{Permeation through Organic Substrates and Inorganic Coatings}

A barrier is defined as the resistance against permeation, i.e., against the mass transfer of gaseous substances through a solid body. The process of permeation involves four main stages: adsorption, absorption, diffusion and desorption [43]. In the first step the molecules are adsorbed onto the substrate surface of the solid material and build up a thin molecule layer by adhesive power. Then, permeating molecules are absorbed and transported through the polymer. The permeation coefficient $(P)$ of molecules is determined by two factors, $(S)$ and $(D)$ (Equation (3)). The solubility coefficient $(S)$ describes the concentration $(c)$ of dissolved molecules in the polymer in dependence of the partial pressure $(p)$ (Equation (1)). The diffusion coefficient $(D)$ describes how fast molecules permeate along the concentration gradient $(\Delta c)$ using intermolecular and intramolecular spaces until a solution equilibrium is established. The diffusion flux $(J)$ of molecules permeating through a homogenous polymer over a certain distance $(\Delta d)$ along the concentration gradient is explained by Fick's first law of diffusion (Equation (2)). Finally molecules are desorbed from the polymer surface and evaporated or removed by other mechanisms. The overall permeability of a polymer $\left(Q_{\text {poly }}\right)$ is then described by the permeation coefficient $(P)$ and the thickness of the material (d) (Equation (4)).

$$
\begin{gathered}
c=S \times p \\
J=-D \times \frac{\Delta c}{\Delta d} \\
P=D \times S \\
Q_{\text {poly }}=\frac{P}{d}
\end{gathered}
$$

The barrier of inorganic coatings is subjected to its chemical composition, the microstructure and homogeneity $[19,26]$. Although a thin evaporated inorganic coating clearly improves the barrier 
properties of polymer substrates, it still shows a permeability that is several magnitudes higher than it would be for a perfectly crystalline material. This can be partially explained by the layer growth and the connected degree of imperfection. Moreover, contamination during the evaporation by other gases or dust, anti-block particles in the substrate, as well as mechanical tensions between the substrate and the inorganic coating play an important role. All these factors may lead to cracks or pores in the coating and thus increase the gas transmission of the polymer and coating $\left(Q_{\text {poly+coat }}\right)$ [44,45]. In relation to the pore size, different mechanisms for permeation are presented in [46]. Nevertheless, the diffusion through macroscopic defects $(100 \mathrm{~nm})$ plays a major role [47]. Given such macroscopic defects, permeation continues as if there was no inorganic coating. According to the current state of the art, a completely defect free inorganic coating cannot be produced by vacuum deposition [48]. However, the determination of the amount and size of pores is rather complex and time-consuming. This is why the barrier improvement factor (BIF) is commonly used to describe the quality of the inorganic coating. This value sets into relation the permeabilities of the polymer with $\left(Q_{\text {polytcoat }}\right)$ and without $\left(Q_{\text {poly }}\right)$ the inorganic coating. It is affected by the amount and size of defects as well as the thickness of the underlying polymer substrate:

$$
B I F=\frac{Q_{\text {poly }}}{Q_{\text {poly }+ \text { coat }}}
$$

Herein, the permeability of the polymer with inorganic coating $\left(Q_{\text {poly+coat }}\right)$, actually consists of the transmission through all defects, assuming that the rest of the surface does not let pass any gas. Trying to describe the permeation through these defects, various models were developed. The first models were created by Prins and Hermans [44], based on which further ideas were presented by e.g., [49-53]. For technically relevant substrate thicknesses and defect sizes, the models can be rewritten approximately as in Equation (6). Herein it is visible, that the transmission $Q_{\text {poly+coat }}$ does not depend on the substrate thickness (within the range of validity), but only on the permeability coefficient $(P)$ of the material, the amount of the defects per area $\left(n_{\mathrm{d}}\right)$ and the effective average of defect area (a) [37]:

$$
Q_{\text {poly }+ \text { coat }} \approx 2 \times P \times n_{\mathrm{d}} \times \sqrt{a}
$$

\subsection{Importance of Coating Thickness for Barrier Properties}

The thickness and consistency of nanodeposited layers (nanocoatings) have a high impact on their performance [54]. Several studies $[37,50,55]$ showed that the permeability $Q_{\text {poly+coat }}$ negatively correlates with the increasing thickness of the inorganic coating until a certain point. Then, even for higher thicknesses, $Q_{\text {poly+coat }}$ stays almost constant. In [37] it was shown that only for thicknesses that are one to three magnitudes higher the permeability further decreases. It was concluded, that the idea of Volmer-Weber growth helps us to understand the steady decrease of permeability for low coating thicknesses. Nonetheless, the few existing investigations that have been made to analyze the coating structure rather indicate a Frank-van-der-Merwe growth.

Figure 2 raised the question of how the thickness of an inorganic coating should be defined. Does "thickness" take blank spaces or defects into account or not? Is "thickness" an average value over a broader surface or is it measured at a certain distinct point? Does "thickness" include aluminum oxide or only pure aluminum? Accordingly, when having a look at various publications [37,39,42,56-60], the thickness is measured by numerous different methods. Because the thickness of these aluminum coatings is much shorter than the wavelength of visible light, traditional microscopy is not usable for this application.

As stated by Mattox [61], these methods can be subdivided into mass, geometrical, and property thicknesses. Mass thickness is measured in $\mu \mathrm{g} / \mathrm{cm}^{2}$ (e.g., by mass spectroscopy) but does not take into account the density, micro structure, composition, or surface morphology. In contrast, the geometrical thickness in measured in $\mu \mathrm{m}, \mathrm{nm}$, or $\AA$ (e.g., AFM, profilometry). This value is affected by the surface morphology (e.g., roughness). Just like the mass thickness, geometrical thickness does not consider 
composition, thickness, or microstructure. By measuring property thicknesses, a physical value is obtained (e.g., electrical resistance, optical density, interference) which is then mathematically related to the coating thickness (see Figure 3).

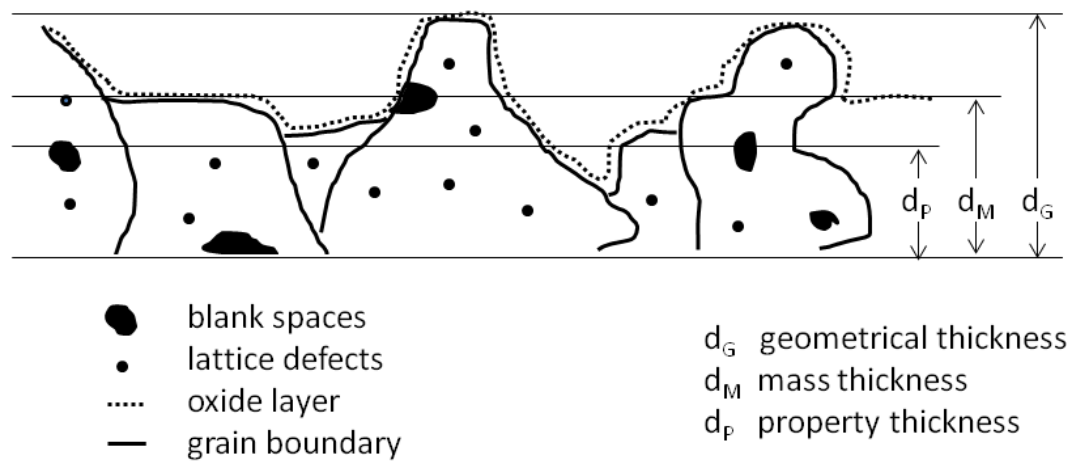

Figure 3. Mass, geometrical, and property thickness.

In the following sections, the quartz micro balance (QMB), mass spectroscopy (ICP-MS), atomic force microscopy (AFM), optical density (OD), interference, electrical surface resistance and eddy current measurements are presented as examples for the methods explained above.

For each technique the theoretical background, the method, and the analyses are explained. Limitations and especially parameters affecting the measured values are highlighted. Yet, especially concerning limitation values, equipment specifications will give more specialized information to the user. This work aims to be used as a guiding handbook for packaging technologists working in the field of metallization. For more detailed information, literature hints are provided for the interested reader.

\section{Characterization Techniques}

\subsection{Mass Thickness}

There are various measurement techniques available today, for determining mass thickness, such as X-ray fluorescence, ion probe, radioactivation analysis, chemical balance, micro balance, or torsional balance [62]. However, the most common method in the field of PVD is the quartz crystal micro balance (QCM), with which the evaporation rate is usually monitored [63]. Taking into account the coating speed and geometrical constraints under which the QCM, the evaporation source and the substrate are arranged, the coating thickness can be calculated in $\mathrm{g} / \mathrm{m}^{2}$. The second method presented here is the analyses via ICP-MS, which is a certain kind of mass spectrometry. This, of course, can only be used when the sample is inserted as a liquid. Therefore, the evaporated aluminum needs to be dissolved from the substrate of distinct area before the amount of aluminum in the sample can be determined.

\subsubsection{QCM}

\section{QCM: Theory}

When alternating current (AC) is applied on to the gold electrodes, which are evaporated on a piezoelectric quartz crystal, the crystal starts to oscillate in its resonance frequency (see Figure 4). A quartz with a thickness of $3.317 \times 10^{-4}$ has a resonance frequency of $5 \mathrm{MHz}$ [64]. For doing so, the crystal needs ideally to be cut from a mono crystal at an angle of $35.1^{\circ}$ toward the optical axis, so that it oscillates in thickness shear mode. The frequency of this oscillation depends on the geometry of the crystal and therefore drops when the thickness increases $[65,66]$. By monitoring the change 
in frequency and relating it to the deposited mass, this effect is used to gain information about the amount of aluminum that is evaporated on the QCM [67].

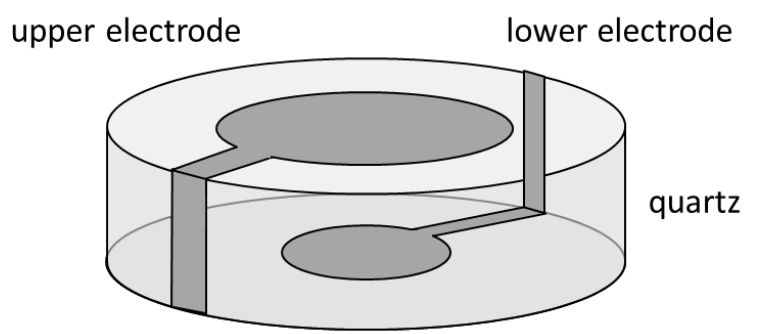

Figure 4. Typical QCM geometry, diameter ca. 10-30 mm, thickness ca. $0.3 \mathrm{~mm}$ (adapted from [64]).

The relation between frequency and mass is based on physical principles, as explained in the following. Commonly, the software will use mathematics to export data about the thickness.

Under the assumption, that the evaporated material (aluminum) behaves similar to the quartz and that the evaporated mass is small in comparison to the quartz (about $2 \%$ ), the resonance frequency changes linearly with the mass increase. Resonance appears, when the thickness of the quartz $(d)$ is half of the transversal wavelength $(\lambda)$ (Equation (7)). The speed of sound $\left(v_{\mathrm{s}}\right)$ in quartz is a constant and dictates possible wavelengths $(\lambda)$ and frequencies $(f)$ (Equation (8)). Consequently, $(d)$ and $(f)$ always have the same proportion, as $\left(v_{\mathrm{s}}\right)$ is constant (Equation (9)). When the evaporated material arrives on the surface, the thickness and mass increase. Therefore, Sauerbrey [68] introduced the mass density $\left(M_{\mathrm{E}}\right)$ for the evaporated material and for the quartz material $\left(M_{\mathrm{Q}}\right)$ which is defined by the thickness $(d)$ and density $(\delta)$ as in Equations (10) and (11). Accordingly, when the thickness $(d)$ increases, also the mass density $\left(M_{\mathrm{E}}\right)$ increases. Consequently, the change in frequency $(\Delta f)$ is related to the mass density $\left(M_{\mathrm{E}}\right)$ as in Equation (12). By combining Equations (8), (11) and (12), Equation (13) can be derived and it becomes obvious, that $(\Delta f)$ directly relates to the mass density of aluminum $\left(M_{\mathrm{E}}\right)$, as $\left(v_{\mathrm{s}}\right),\left(\delta_{\mathrm{Q}}\right)$ and $(f)$ are constant. This correlation was first mentioned by Sauerbrey [68] and is therefore denoted as the Sauerbrey-equation [66]. For further improvement of the mathematical model, the impedance values for each plane can be introduced when modeling them as coupled resonators from two planes. A precise overview is given in [65].

$$
\begin{gathered}
d=\frac{\lambda}{2} \\
v_{\mathrm{s}}=\lambda \times f \\
\frac{\Delta d}{d}=-\frac{\Delta f}{f} \\
M_{\mathrm{E}}=d_{\mathrm{E}} \times \delta_{\mathrm{E}} \\
M_{\mathrm{Q}}=d_{\mathrm{Q}} \times \delta_{\mathrm{Q}} \\
\Delta f=-f \times \frac{\Delta M_{\mathrm{E}}}{M_{\mathrm{Q}}} \\
\Delta f=-2 f^{2} \times \frac{M_{\mathrm{E}}}{\delta_{\mathrm{Q}} \times v_{\mathrm{s}}}
\end{gathered}
$$

QCM: Method

The QCM is commonly integrated in the machine at some point close to the evaporation source and the process roll. It has to be taken into account, that at the place where the aluminum is deposited on the QCM, there is a shadowing effect so the aluminum will not reach the substrate surface. Additionally, the angle $(\alpha)$ and distance towards the evaporation source should be taken into account, as this might alter the measured results (see Figure 5). 


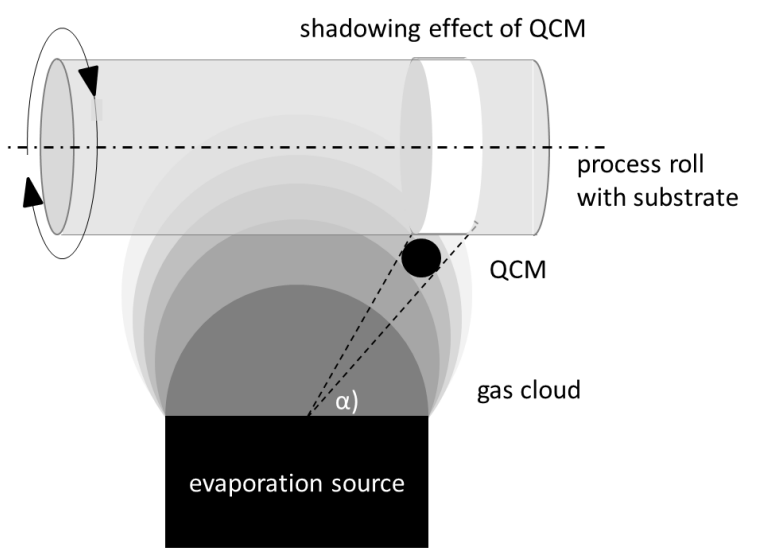

Figure 5. Arrangement of a QCM in the vacuum deposition unit.

\section{QCM: Practical Aspects and Analyses}

The software commonly needs the material density as input and its output will commonly be the deposition rate in $\AA$ /s. The accuracy is about $2 \%$. The accuracy decreases with increasing thickness, which is why there are a few methods to reduce this effect. One option is to use a shutter, which only lets aluminum pass on the QCM in a certain frequency. Or a filter could be used, which only lets a certain number of atoms pass through to the QCM. Like this, the actually arriving amount of aluminum can be extrapolated, while at the same time the layer thickness on the QCM is reduced. Of course, this will reduce the accuracy of the QCM $[15,67,69]$. It has to be taken into account that the value obtained is the deposition rate and has the unit $\AA$ /s. The faster the material moves, the lower the coating thickness will be. The coating thickness $(t)$ can be approximated by the following Equation (14), taking into account the deposition rate $(x)$, the web speed $(w)$ and the shutter width $(y)$ :

$$
t=x \times \frac{w}{v}
$$

\subsubsection{ICP-MS}

\section{ICP-MS: Theory}

ICP-MS (inductively coupled plasma mass spectrometry) is based on the chemical dissolution of the aluminum and the subsequent measurement of the concentration of aluminum in the dissolution. There are quite a few different ICP methods available for detecting unknown substances. The major concurring method that needs to be mentioned is ICP-OES (inductively coupled plasma optical emission spectrometry), in which electrons are excited, and the photons that are emitted when the electrons fall back to their ground state, are detected. In comparison, in ICP-MS, the plasma is used to ionize atoms and the ion charge is used to detect them. However, even for ICP-MS there are various equipment designs available today, of which three are outlined. An extensive overview is given in [70].

The ICP-MS basically consists of three main parts: the probe- and plasma unit, the cones, and the mass spectrometer. Firstly, the liquid probe is conveyed over the pump and the vaporizer into the spray chamber. The small droplets are then transferred into the plasma unit. The plasma unit involves an induction coil that produces a high-frequency electromagnetic field. Argon is inserted in this field and becomes plasma, which is "seeded" with electrons [70]. When the small gas droplets reach the plasma, they are dried, decomposed, atomized and ionized. Afterwards, the positively charged ions pass through two concentric quartz cylinders (sampling cone, skimmer cone) where non-ionized atoms are excluded. The cones also lead to a focusing of the ion beam (Figure 6). 


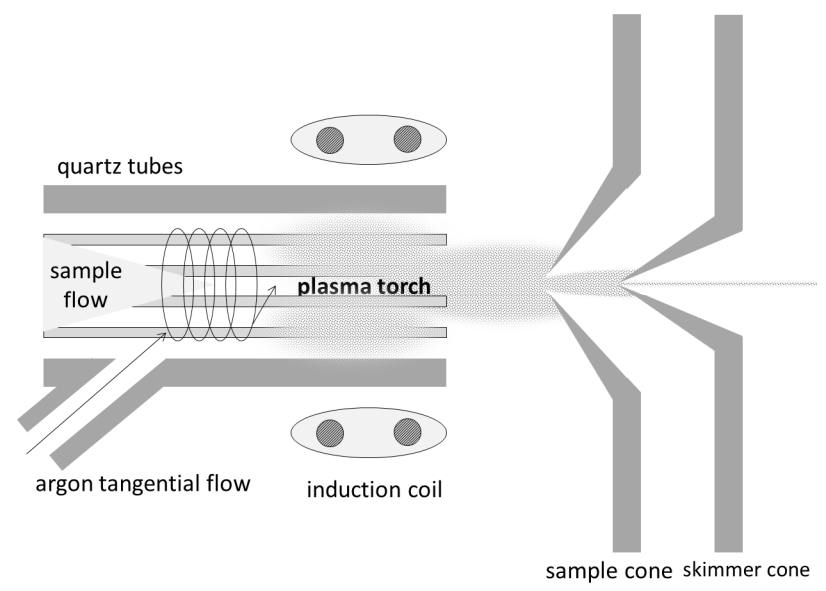

Figure 6. Plasma unit and torch in ICP-MS (adapted from [70-72]).

In a mass spectrometer, three basic principles are used, namely quadrupole filters, magnetic analyzers, and time-of-flight analyzers. In the first case, the ions pass a quadrupole or even octopole reaction system. This element consists of four or eight dipoles with opposite directions. On the opposing dipoles, a combination of DC and AC potentials is applied. A positively charged ion will be torn towards the negatively charged rod and discharged, unless the voltage changes before the collision. When the voltage changes before collision, the ion changes its direction. Like this, depending on their mass to charge ratio $(\mathrm{m} / \mathrm{z}$ ) ions start to oscillate and can only pass the quadrupole if they have a distinct $m / z$-value for a given frequency (Figure 7) [65,71]. All other ions will impact on the surface of the quadrupole or the sled wall and are discharged. Within one measurement, typically one mass is detected after another. Additionally, a helium collision mode is available. In this mode, helium is inserted in the quadrupole and leads to collisions with the sample ions. As molecular ions have bigger dimensions, they tend to collide more often with helium atoms and consequently lose kinetic energy (KED, kinetic energy discrimination). Like this, they are rather easily torn towards the quadrupole rods and can be excluded more easily while passing the magnetic field.

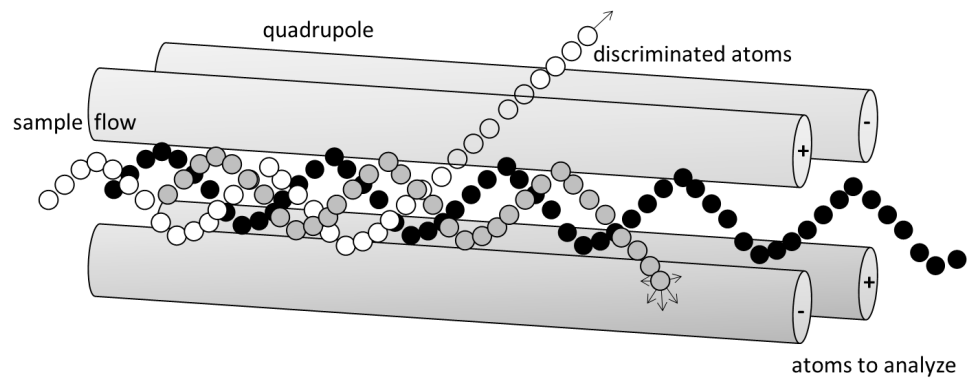

Figure 7. Quadrupole filter (adapted from [70-72]).

In a magnetic analyzer, the ions pass an electric field. When a particle, charged with the load $(q)$ (Equation (15)) is accelerated in an electric field, its kinetic energy $\left(E_{\mathrm{k}}\right)$ and velocity $(v)$ depend on the voltage $(U)$ (Equation (16)). When this accelerated ion passes a magnetic field that is perpendicular to the trajectory, it is deflected and follows a circular path (Figure 8), on which the centrifugal force equals the magnetic force (Equation (17)). The magnetic force is defined by the magnetic field strength $(B)$. By combining Equations (16) and (17), Equation (18) is deducted. It becomes obvious, that the radius $(r)$ is related to the $m / z$-ratio and that by a local dissolution of impinging ions on the detector, the abundance of each $m / z$-specie can be observed [73].

$$
q=z \times e
$$




$$
\begin{gathered}
E_{\mathrm{k}}=\frac{m \times v^{2}}{2}=q \times U \\
q \times v \times B=m \times \frac{v^{2}}{r} \\
r=\frac{\sqrt{2 \times m \times E_{\mathrm{k}}}}{q \times B}
\end{gathered}
$$

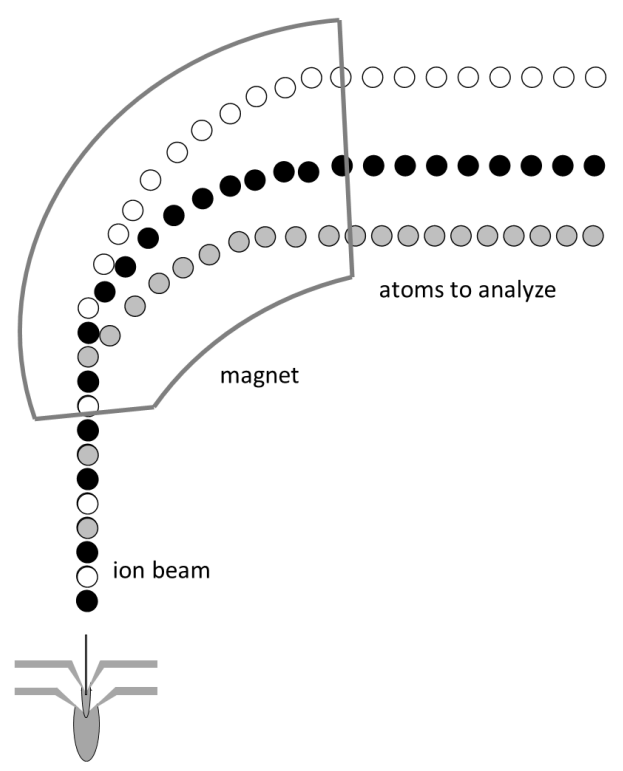

Figure 8. Magnetic analyzer (adapted from [70]).

In a time-of-flight measurement the ions are first accelerated in an electric field and then enter a field free region (Figure 9). As already revealed in Equation (16), the speed at the end of the electric field depends on the mass $(m)$ and charge $(q)$. As all ions have the same charge, the speed $(v)$ is defined by the mass $(m)$. For then passing a certain distance $(L)$, the ions will need the time $(t)$ at a given velocity (v) (Equation (19)). By combining Equations (15), (16) and (19), the time of flight ( $t$ ) can be used to calculate the $m / z$-ration of ions, when $(L)$ and $(U)$ are kept constant (Equation (20)) [71]. An overview of interferences between atoms with the same $m / z$-ratio is given in [74].

$$
\begin{gathered}
L=v \times t \\
t^{2}=\frac{m \times L^{2}}{z \times e \times 2 \times U}
\end{gathered}
$$

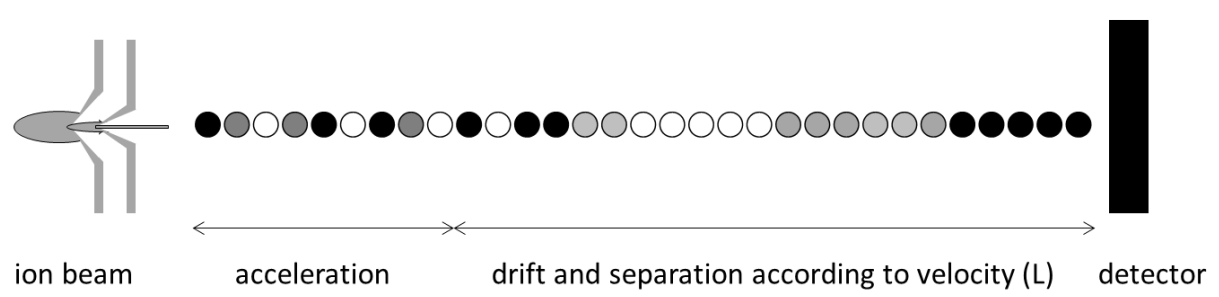

Figure 9. Time of flight measurement (adapted from [70]).

After the mass spectrometer, the ions need to be detected and quantified. As detection systems, three main working functions are available. Either the charge is directly measured (Faraday cup), 
or the kinetic energy transfer (which depends on the mass and velocity of the ions) leads to secondary electrons which are detected. In each case, the impacting ions lead to an electric current that is proportional to the amount of ions that are counted per second. Correspondingly, the resulting value is CPS (count per second) [71].

A quantitative identification of atoms in a probe is possible by standard dissolutions, as there is a linear relationship between the signal intensities of the ions (counts per second, CPS) and the concentration of the element [72,73].

\section{ICP-MS: Method}

For calibration, an aluminum standard dissolution is used. This should be diluted with double distilled water to concentrations of, e.g., $0.25,0.50,1.00,1.50,2.00$, and $3.00 \mathrm{mg} / \mathrm{L}$ aluminum. The software automatically calculates the counts per second (CPS), which is associated with the relating dilution and draws a standard graph (Figure 10).

For the analysis of the aluminum content of the samples, those should be cut to a defined surface (A), e.g., $10 \mathrm{~cm}^{2}$. In the next step, the aluminum of each sample is dissolved by a defined factor $\left(f_{1}\right)$ in 1 molar $\mathrm{NaOH}$, e.g., $50 \mathrm{~mL}$. After dissolving the aluminum for a certain time, the sample can again be diluted with double-distilled water by a factor $\left(f_{2}\right)$. The concentration $(c)$ in $\mu \mathrm{g} / \mathrm{L}$ of this double diluted sample is then analyzed in the ICP-MS as counts per second (CPS) and then related to the concentration by the standard graph.

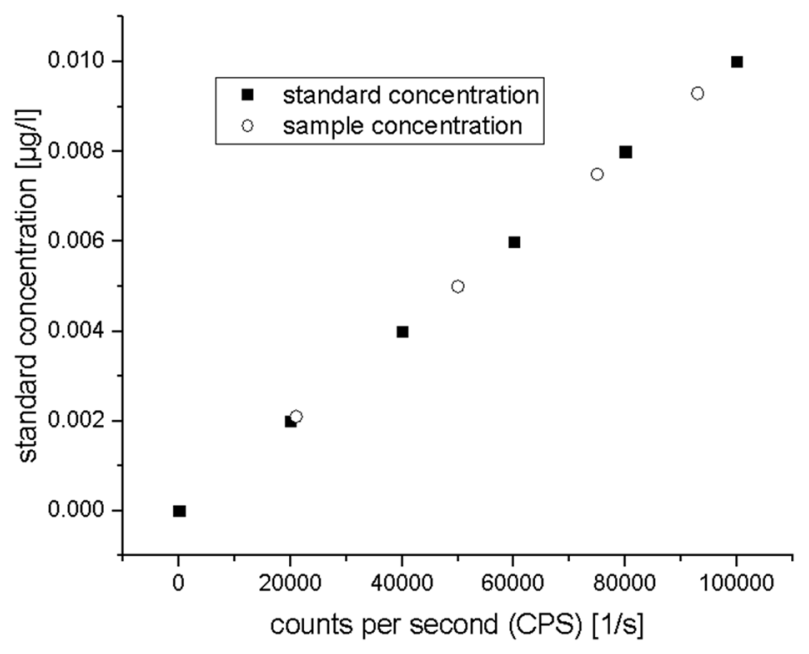

Figure 10. Example of a standard graph for correlation of CPS and standard concentrations.

In order to reach trustworthy results, the following needs are formulated in [70]:

- Complete dissolution;

- Highly pure reagents;

- No chemical interaction between equipment and reagents;

- No loss of analyte.

When it comes to the interpretation of the measured values, it needs to be considered that this value is related to a certain area of the tested material. Whereas the thickness determined via QCM is only valid for a certain location in relation to the evaporation source, the thickness determined via ICP-MS is more of an average value for a whole area. When the measurement area is taken from the same place, where the QCM is usually measuring, the values should be comparable. However, it cannot be compared to, e.g., the area right above the evaporation source, as the thickness will be higher there due to the cosine distribution. 
ICP-MS: Practical Aspects and Analyses

Under consideration of the dilution factor $\left(b_{1}\right)$ and $\left(b_{2}\right)$, the sample surface $\left(a_{\mathrm{s}}\right)$ and the theoretical density $(\delta)$ of aluminum, the thickness $(d)$ of the evaporated coating can be calculated according to Equation (21).

$$
d=\frac{c \times b_{1} \times b_{2}}{a_{\mathrm{s}} \times \delta}
$$

When using this value, it should be considered that this method determines all the aluminum in the sample: aluminum existing as oxide as well as the pure metal, which might explain the deviations from other methods [42]. Additionally, interferences between atoms with the same $m / z$-ratio might alter the results. An overview of those is given in [74]. Limits of detectable concentrations (c) for diverse elements are given in [71] and range from 0.001 to $>10 \mu \mathrm{g} / \mathrm{L}$. For aluminum, the range is $0.001-0.1 \mu \mathrm{g} / \mathrm{L}$. This range can further be exploited by increasing or decreasing the dilution factors $\left(b_{1}\right)$ and $\left(b_{2}\right)$ or sample surface $\left(a_{\mathrm{s}}\right)$, as given in Equation (21).

\subsection{Geometrical Thickness: AFM}

AFM is a contact profilometry method. In contrast to contact profilometry, non-contact profilometry uses electrons or photons for scanning the surface and gathering information about the depth profile. Contact profilometry methods are mechanical stylus profilometers, AFM and STM (scanning tunneling microcopy). In the latter, a cantilever is brought in such a short distance to the surface, that electrons start to tunnel and the current is measurable. As the current is then proportional to the distance, a surface topography image can be obtained. The AFM is based on a mechanical scanning of surfaces with the help of a cantilever with a sharp probe on top. This probe is moved across the surface line by line. In consonance with the surface topography, the cantilever is deflected and the extent of bending can be measured with capacitive or optical sensors. This information is translated into a surface topography image.

\subsubsection{AFM}

\section{AFM: Theory}

When the probe approaches the surface, depending on the distance, different interaction forces superimpose. Van-der-Waals forces which are indirect proportional to $-\left(r^{6}\right)$, appear due to charge transfer and act attractive. At smaller distances, orbital overlaps produce repulsive forces. They are indirect proportional to $r^{12}$. When superimposing both potentials, the resulting Lenard-Jones-potential shows the dependency of attractive and repulsive forces of the distance between probe and surface (Figure 11). As the probe approaches the surface, the cantilever ideally shows no bending. Then a "snap in" occurs, when attractive forces start to dominate. At this point, the probe starts to touch the surface. When the cantilever is further pressed against the surface, it is deflected and the repulsive forces dominate. Due to this effect, not only the imaging of topography but even the resolution of single atom orbitals is possible. For operating the AFM two different procedures are possible, one of which is in the field of "attractive forces" and the other one in the area of "repulsive" forces [75].

\section{AFM: Method}

Basically, three different modes are available for AFM measurements: contact mode, non-contact mode, and intermitting mode. In the contact mode with constant height, the probe is moved so close to the surface that it is bent. According to the extent of bending (repulsive forces), the surface topography is imaged. However, in this mode, the surface and probe might be injured and hence the nature of the surface might affect the results. 


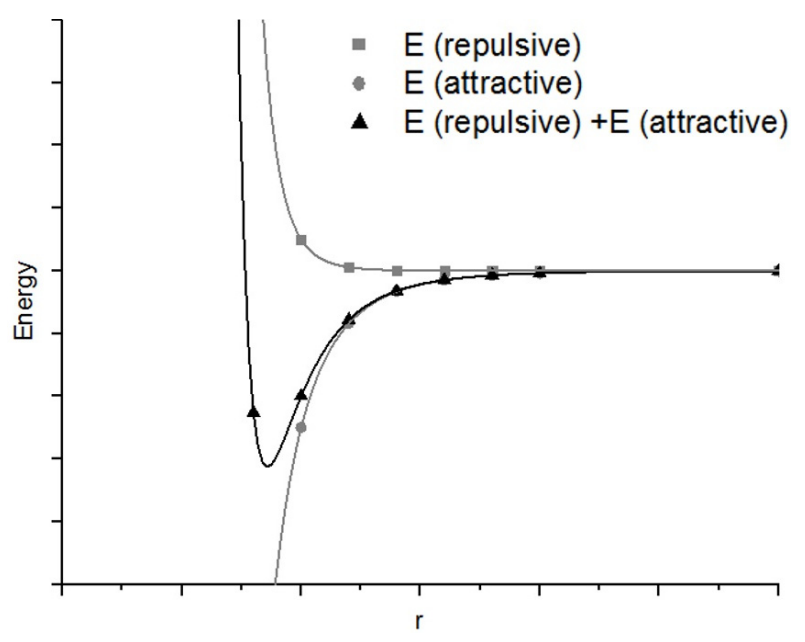

Figure 11. Lennard Jones potential (adapted from [76]).

In the contact mode with constant force, the deflection of the cantilever is adjusted permanently to a set point that is especially useful for soft matter. In order to optimize the outcome, the set point needs to be adjusted in dependence of the cantilever stiffness and the surface nature. Information about the topography can then be extracted from the adjusted height of the cantilever. The advantages of this mode are the high resolution and that the probe and surface are protected.

In the non-contact mode, the cantilever oscillates at its resonant frequency. As the cantilever comes near the surface, it interacts with the force field (attractive forces), which quenches the oscillation and affects frequency and amplitude. Based on the phase and amplitude shift, information about the surface topography is deduced.

In the intermitting mode, the cantilever oscillates just like in the non-contact mode. Still, the distance between probe and surface is continuously adjusted to a constant level by keeping the interaction steady [75]. The advantage is that, apart from topography, stiffness and adhesion can also be determined by separately capturing attractive and repulsive forces [77]. As stated by Eaton and West [75], more than 20 different modes of AFM are available today. Therefore only the basic principles are outlined in this review.

All modes use the same basic function, as explained in the following. The surface of the sample is scanned line by line. Therefore, either the sample or the cantilever can be moved. As described before, based on the interaction between cantilever and sample surface the cantilever is deflected vertically. While the probe moves across the surface, the bending of the cantilever is measured by optical sensors (Figure 12). In this optical sensor a laser beam impinges on the backside of the reflective cantilever and the movement of the reflected light spot is measured by a photodetector. Thus when the probe touches the surface, the light spot moves and the feedback control reacts by increasing the voltage output. Following the increase of voltage, a piezoelectric device will expand and lets the probe move away from the surface (approximately $0.1 \mathrm{~nm}$ per applied volt). The voltage used to move the piezo element in the $\mathrm{z}$-direction is monitored and the height topography can be imaged accordingly $[75,77,78]$.

The resolution power of the AFM is limited by the geometry of the cantilever. Due to the respective geometries there is a real and an imaginary point of contact between probe and surface during scanning. Mathematically speaking, the measurement is a convolution between probe geometry and the surface (Figure 13). Consequently, elevations are depicted larger (Figure 13c,d) and indentations are represented smaller (Figure 13a,b) than they really are. Thus the geometry of the probe is critical to the quality of the images measured with an AFM [75]. 


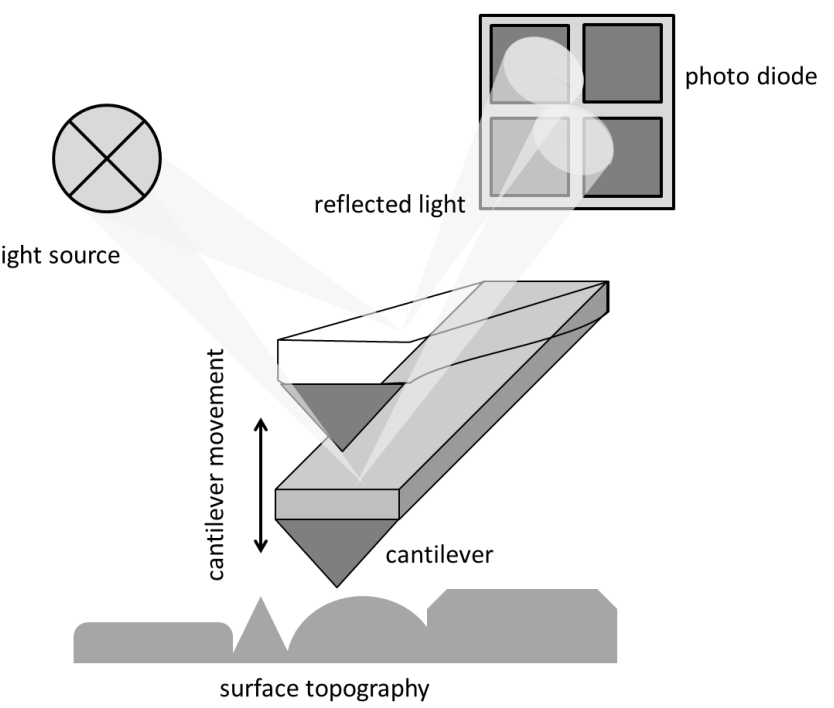

Figure 12. AFM equipment (adapted from [77]).

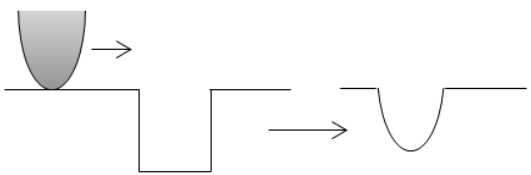

(a)

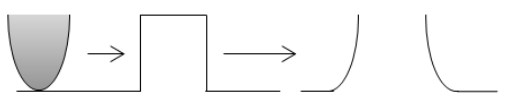

(c)

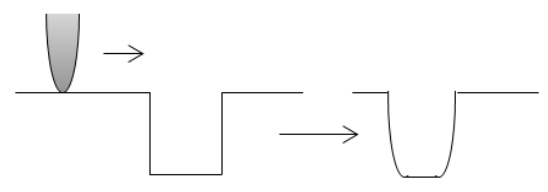

(b)

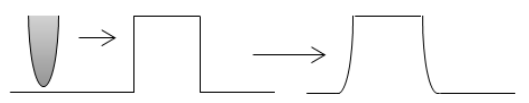

(d)

Figure 13. AFM operation (adapted from [75]) $(\mathbf{a}, \mathbf{b})$ smaller representation of indentations and (c,d) larger representation of elevations.

The cantilever with the nm-scale probe on top is usually produced by MEMS (Micro-Electro-Mechanical Systems) technology. The materials used are commonly $\mathrm{Si}_{3} \mathrm{~N}_{4}$ or $\mathrm{Si}$ which show a diamond-like structure. Whereas $\mathrm{SiN}_{4}$ cantilevers tend to bend due to residual stress, Si probes have a tendency to chip while contacting the surface [75].

For measuring the thickness of evaporated aluminum, an adhesion tape needs to be applied on the surface before evaporation (Figure 14). Afterwards, the adhesion tape is removed and a clear edge between the aluminum coated surface and the area, that was covered by the adhesive tape, appears. In this area, the measurements can be done by AFM. The measurement area can be adjusted between a few $\mu \mathrm{m}$ to up to $100 \mu \mathrm{m} \times 100 \mu \mathrm{m}$.

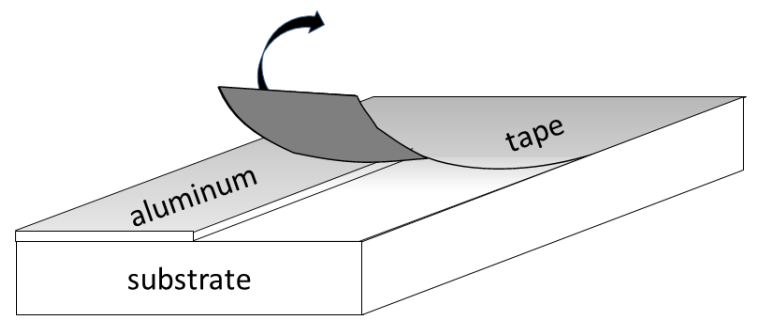

Figure 14. AFM measurement surface. 


\section{AFM: Practical Aspects and Analyses}

Based on the measured topography (Figure 15) cross sections perpendicular to the edge are drawn and height profiles are extracted (Figure 16). The coating thickness can now be calculated by the height difference between the surface with and without aluminum. The peak in the middle of the graph in Figure 16 is a result of the tearing of the adhesive tape. By tearing, the aluminum is slightly lifted on the edges. Therefore, the peak area must not be considered. Moreover, the base line might not be as ideally horizontal as in Figure 16. In this case, the extracted height profile must be transcribed into an Excel file. Here, the data points from the base line of the substrate can be used to approximate a linear curve. Then the intercept of the curve is moved up so that the base line for the substrate plus coating can be fitted. By using a cosine function, a perpendicular can be dropped between the two baselines in order to calculate the distance between them.

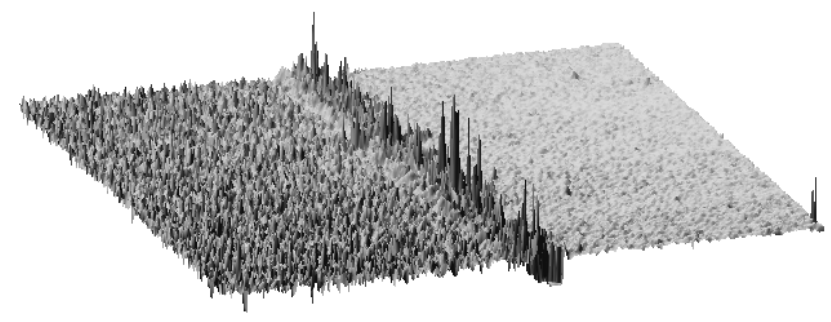

Figure 15. Example of a surface topography.

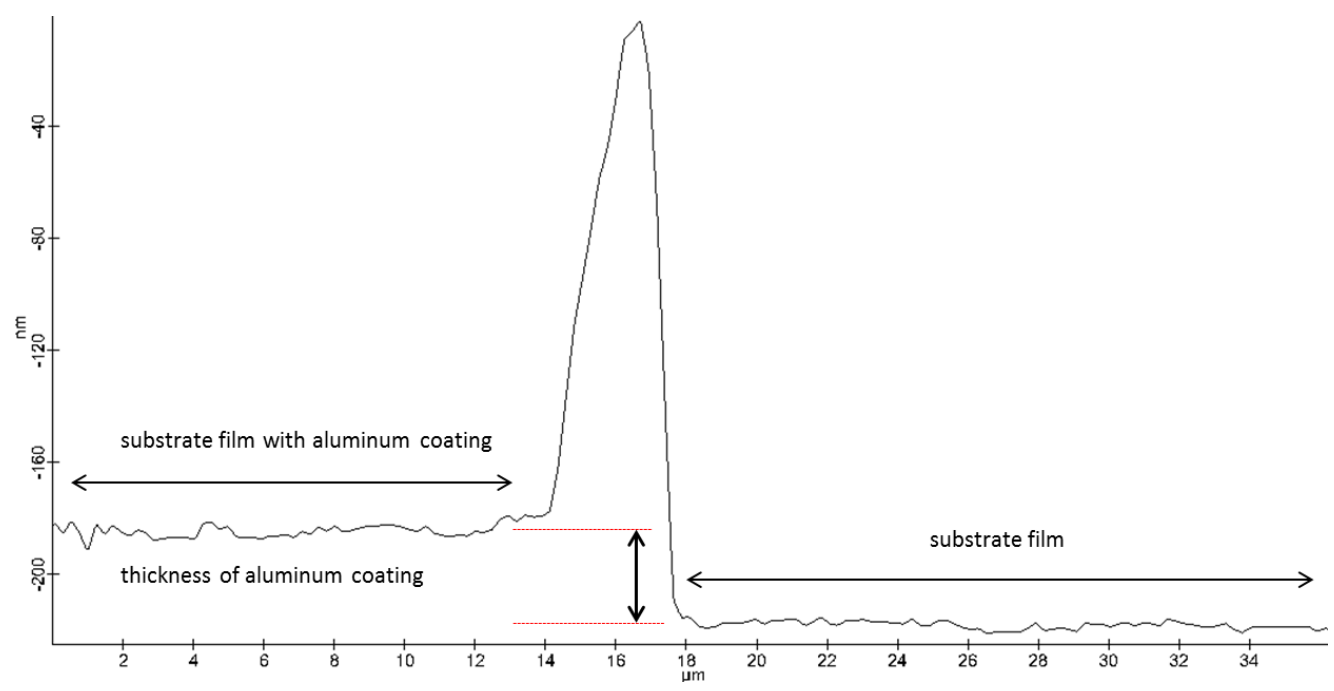

Figure 16. Example of an extracted profile.

What has to be taken into account when using this method is that that aluminum oxide is not captured separately but is included in the measured value. Additionally, inclusions, blank spaces, voids, etc. are not recorded either. The measurement is quite punctual, because it is not practical to make measurements on areas greater than about $100 \mu \mathrm{m} \times 100 \mu \mathrm{m}$. Scanning larger areas would lead to long scanning times in the range of a few hours. However, the resolution is extremely high and apart from height information, knowledge about the single molecule interactions between surface and cantilever (e.g., surface tension) can be gathered [75]. As displayed in Figure 13, the image that is acquired is strongly affected by the cantilever that is used. This effect can be diminished, when profile information is not only gathered in one scan direction but in backward and forward measurement modes. That means that each unevenness is captured from both sides. The resolution of AFM is commonly greater than $100 \mathrm{~nm}$, reaching up to atomistic scales. Commercial specimens for $\mathrm{Z}$ calibrations are even available to a size of $2 \mathrm{~nm}$ [75]. 


\subsection{Property Thickness}

Whereas the last two chapters described the geometrical and mass thickness of thin coatings, this chapter focuses on the so-called property thickness. This denomination originates from the fact, that not the material itself, but the interaction with another physical phenomenon, e.g., ions, neutral particles, electrical field, or thermal energy, is monitored. In the present case, the interaction with photons (optical density, interference) and electrons (electrical surface resistance, eddy current measurement) is used to further describe thin aluminum coatings [65]. Other methods that can be counted as property thickness measurements are the Hall voltage measurement, interference spectra, polarization analysis, beta backscattering, $\mathrm{X}$-ray fluorescence, $\mathrm{X}$-ray emission, energy dispersive $\mathrm{X}$-ray spectroscopy (EDX), and others [65].

\subsubsection{Optical Density}

Any optical phenomenon is connected with the reaction of light with matter. Light can generally be considered as a superposition of electromagnetic waves, which interact with the substrate so that amplitude, wave length, angular frequency, intensity, polarization, and propagation direction changes. For all optical methods, one or more of these characteristics is observed and then related to the material features [79]. Examples are: total reflection X-ray fluorescence analysis (TXRF), energy-dispersive $\mathrm{X}$-ray spectroscopy (EDXS), grazing incidence X-ray, glow discharge optical emission spectroscopy (GD-OES), reflection absorption IR spectroscopy (RAIRS), surface-enhanced Raman scattering (SERS), and UV-Vis-IR ellipsometry (ELL) $[65,80]$. When the correspondent signals are analyzed, one will usually achieve information about the surface of the probe and/or about the material itself. However, especially when thin coatings are analyzed, both effects superimpose. This problem is often solved by building mathematical models that incorporate both phenomena. Then the model is fitted to the measured values. Like this, information about both (geometry and material) can be derived. Though for doing so, a minimum knowledge about the materials (e.g., refractive indices, absorption coefficients, approximate thicknesses, etc.) in the probe is necessary before fitting the measurement with the mathematical model [79]. The method of measuring the optical density uses the intensity of light as a characteristic feature. The material specific property that has to be known for this kind of analyses is the absorption coefficient $(\alpha)$, as explained in the following.

\section{Optical Density: Theory}

When light impacts a surface, it will partially be reflected $(R)$, absorbed $(A)$, scattered $(S)$, and transmitted (T). Because of the conservation of energy, the sum of all parts is always 1 (Equation (22)). By knowing three of them, the fourth one can easily be calculated. However, reflection $(R)$ and transmission $(T)$ are rather easy to capture. Consequently, $(A)$ and $(S)$ are often summarized to the optical loss (L), as they are rather hard to define (Equation (22)). Commonly, the parts of reflected, absorbed, scattered, and transmitted light are defined by their relation to the initial intensity of the light beam (Equation (23)) [79,81].

$$
\begin{gathered}
R+A+S+T=1=R+L+T \\
R \equiv \frac{I_{\mathrm{R}}}{I_{0}} \quad S \equiv \frac{I_{\mathrm{S}}}{I_{0}} \quad A \equiv \frac{I_{\mathrm{A}}}{I_{0}} \quad T \equiv \frac{I_{\mathrm{T}}}{I_{0}}
\end{gathered}
$$

Apart from that, Lambert and Beer introduced a mathematical law concerning absorption, which is commonly used in biology and chemistry to find the amount of dispersed particles in a liquid. They found that the intensity of transmitted light correlates with the absorption coefficient of the particles $(\alpha)$ and the distance $(l)$ that light travels through the dispersion according to Equation (24). 
The absorption coefficient $(\alpha)$ in turn is linked to the frequency $(\omega)$, speed of light $(c)$ and extinction coefficient (K), as illustrated in Equation (27) [79].

$$
\begin{gathered}
I_{\mathrm{T}}=I_{0} \times e^{-\alpha 1} \\
\alpha=2 \times \frac{\omega}{c} \times K(\omega)
\end{gathered}
$$

This means that according to the Lambert Beer law, absorbance $\left(A^{\prime}\right)$ is defined as the part of the light that is not transmitted (Equation (26)). This definition of "absorbance" does not equal the definition given at the beginning of the paragraph but is rather defined by absorption $(A)$, scattering $(S)$, and reflectance $(R)$, as becomes obvious in Equation (27). Nevertheless, the optical density (OD) (Equation (27)) is derived from Equation (24) and is used to characterize the thickness of thin coatings. That means a coating having an optical density of 1,2 or 3 lets pass $10 \%, 1 \%$ and $0.1 \%$ of light, respectively. Consequently, when using the concept of optical density, one needs to be aware that scattering, reflectance and absorption might alter the measured value although the originally defined absorbance might have kept constant. Additionally all four values are subjected to the wavelength, material, and the material's structure $[79,81,82]$.

$$
\begin{gathered}
T=1-A^{\prime} \\
\alpha l=-\log \frac{I_{\mathrm{T}}}{I_{0}}=-\log (1-A-S-R)=O D
\end{gathered}
$$

Optical Density: Method

Because of the above-mentioned simplification, only the transmittance is measured for optical density [39]. Some simpler or rather sophisticated methods are commercially available. They all have in common that, for measuring the transmittance, the object is placed under a focused light source and transmittance is measured by a photo diode on the backside of the material. Depending on the equipment, one single wave length or a whole range can be measured (e.g., with FTIR). As evaporated coatings are typically applied on polyethylenetherephthalate or polypropylene substrates, the optical density of the pure substrate should also be captured and subtracted from the measured value.

Optical Density: Practical Aspects and Analyses

Weiss [83] showed in his work a linear correlation between optical density and thickness in the range of optical density of 0.3 to 3.5 (this means a transmission of $50 \%$ to $0.03 \%$, respectively). However, the thickness suddenly increases at optical thicknesses $<3.5$. Similarly Hertlein [81] declares that OD is not useful for values $>3.2$. Apart from that, Copeland and Astbury [39] showed, that the optical density decreases over time, as the light-absorbing aluminum reacts to the transparent aluminum oxide. Therefore, the acquired value only takes into account the metallic part of the coating.

Apart from that, the challenge while calculating the thickness of the coating based on the optical density is the definition of the absorption coefficient $(\alpha)$, and the extinction coefficient $(K)$. As mentioned before, these parameters are highly susceptible on material, wavelength, and structure. It was calculated for various other evaporated substances in [84-88]. The interrelation of optical density or transmittance with process conditions, coating thickness and wavelength was evaluated by $[42,89,90]$. According to Schulz [91], the absorption coefficient for aluminum has a value of approximately $4-9$ for wavelengths of $0.4-0.9 \mu \mathrm{m}$. As stated by Lehmuskero and Kuittinen [89] the coefficient had a value of 3-21 for a wavelength of 0.3-2 $\mu \mathrm{m}$. Heavens [92] gave an overview of coefficients determined by various sources. Here, the extinction coefficient attained values of 0-12 in the region of $0.1-100 \mu \mathrm{m}$ wavelength. Moreover, Lehmuskero and Kuittinen [89] found that the values for atomic layer deposited aluminum were higher than for physical vapor deposited aluminum. This was explained by the higher grain size for evaporated coatings, which leads to a reduced scattering of electrons, which in turn 
increases the absorption coefficient. Apart from that, the coating thickness showed an effect over the whole range of wave lengths without showing a clear trend. One way to explain this effect was to take into account the aluminum oxide. Depending on the overall thickness, the oxide layer might occupy different portions of this thickness and might therefore have different impacts on the optical density. However, this was not evaluated further. As a conclusion, Lehmuskero and Kuittinen [89] recommended, not to use literature values for extinction and absorption coefficients, as these might lead to deviations of approximately $20 \%$ but rather identify them for each new process and process equipment. Consequently, the method can be used as a fast way of obtaining approximate thickness evaluations, especially when the process conditions are kept constant. However, the coefficients need to be clearly determined when very accurate values shall be obtained. In this case, the identification of these values might be extremely time consuming.

\subsubsection{Interference (Tolansky Method)}

In 1827 the physicist Jacques Babinet proposed the idea of using the wavelength of light as a measure of length, which is basically done in interferometry [93]. As elucidated previously, the interaction of light with matter alters the amplitude, wave-length, angular frequency, intensity, polarization, and / or propagation direction [79]. The interference method uses the reflectance $(R)$ of surfaces as well as the intensity $(I)$ of light.

Interference is the superimposition of rays, which can be non-destructive or destructive in the case of coherent waves, and a phase shift of a half wavelength. If rays are reflected on a surface and superimpose with itself at a phase shift of a half wavelength, then the intensity becomes zero. This effect is visible as bright and dark lines (interference pattern) and can therefore be used to measure coating thicknesses, as is demonstrated in the following Section [93].

For thin coating analyses, a huge number of measurements based on interference is available, which are principally divided into single and multiple beam interferometry. The latter has the advantage that the intensity at each interference band is an accumulated intensity of each reflection and therefore the bands are rather sharp and easy to identify. Further examples are the Michelson interferometry, Fourier spectroscopy, and Fabry-Perot Interferometry.

\section{Interference (Tolansky Method): Theory}

The thickness of a deposited aluminum coating can be determined by the light interference method according to Tolansky [94], which is based on Newtonian interference bands. Knowledge about material density, electrical conductivity, etc. is not necessary [95]. The prerequisite for this method is access to an edge on the substrate, as illustrated in Figure 14. Additionally, both surfaces (aluminum and underlying polymer) should have a high (ideally identical) reflection. If this is not the case, an additional nano meter thin coating of e.g., gold should be sputtered on both surfaces. For creating an interferable system, a semitransparent reference glass is positioned on the sample surface under a small angle $(\alpha)$. Rays will pass through the glass, impact on the probe surface, and be reflected by it with a phase shift of $180^{\circ}$. Incoming and reflected rays will then interfere. For doing so, these rays need to have a minimum distance. This is achieved by a small distance between the glass and the surface as well as a small angle between both. When the distance between the substrate surface and the reference glass is a multiple of $0.5 \lambda$, waves superimpose in a destructive way and interference bands appear in a defined distance $(a)$. Due to the small angle and low distance, interference bands are highly contrasting with a step loss in intensity. They will appear very thin compared to their distances (a) and are therefore usable for an evaluation [96]. Because of the step due to the aluminum coating, there is an offset $\left(a^{\prime}\right)$ between the interference bands caused by the polymer surface and the bands caused by the aluminum surface. The higher the aluminum thickness $(d)$, the bigger the offset $\left(a^{\prime}\right)$ (Figure 17) [94,95,97]. A mathematical description of the dependencies based on simple trigonometric 
relations allows for deriving Equations (28) and (29). By combining both, the thickness $(d)$ is then calculated like in Equation (30) [98,99].

$$
\begin{aligned}
& \tan \alpha=\frac{d}{a^{\prime}} \\
& \tan \alpha=\frac{\lambda / 2}{a} \\
& d=\frac{\lambda \times a^{\prime}}{2 \times a}
\end{aligned}
$$

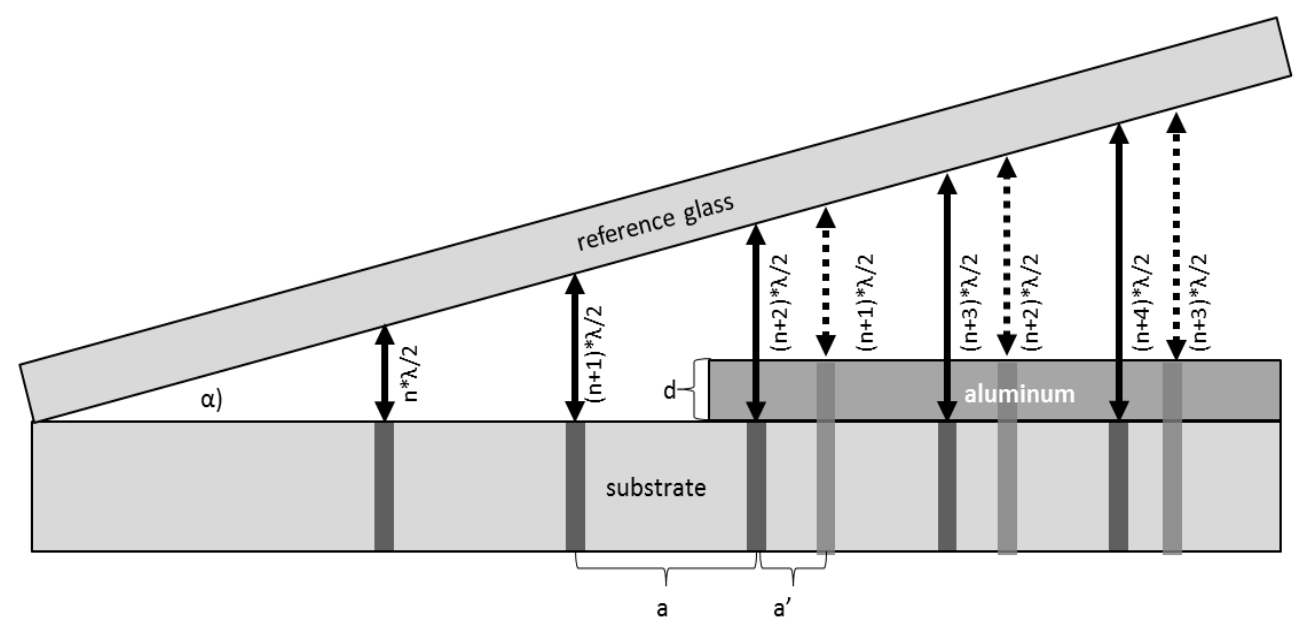

Figure 17. Appearance of interference bands on the semitransparent reflecting coating.

Interference (Tolansky Method): Method

According to the theory described before, only the wavelength $(\lambda)$ as well as the distance $(a)$ and offset $\left(a^{\prime}\right)$ need to be known/measured, for calculating the coating thickness $(d)$. Ideally, both surfaces should have the same refractive index. This is why an additional sputtered coating is often applied on both the polymer and the aluminum. For generating the interference bands, a Tolansky objective is applied on the light microscope and a filter is added for adjusting the light to monochromatic rays of $550 \mathrm{~nm}$. The microscopic objectives that are necessary for interference measurements are commercially available. They are working on the basic principle depicted in Figure 18. Light is emitted and condensed by a lens, then filtered by a monochrome filter to a wave-length of typically $550 \mathrm{~nm}$. Condensed by a second lens and mirrored towards the reference glass, the step between the aluminum and the substrate triggers interference bands, which are then visible and ready to be evaluated by microscope software. The interference bands should be perpendicular to the direction of the coating edge. Once the resolution is adjusted, $(a)$ and $\left(a^{\prime}\right)$ is measured and $(d)$ is calculated as in Equation (30).

Interference (Tolansky Method): Practical Aspects and Analyses

Figure 19 shows typical interference bands of an aluminum coating on a PET surface. Care needs to be taken to correctly identify $(a)$ and $\left(a^{\prime}\right)$. One possibility to facilitate this was presented by Hanszen [95], who explained that, due to the different phase shifts of monochromatic light on the substrate and coating, both should be covered with an additional, highly reflective $10 \mathrm{~nm}$ coating (e.g., gold or silver). This is especially important, when the thickness of the transparent aluminum oxide layer should be included in the measured value. However, roughness, blank spaces between aluminum coating, and sputtered coating, as well as gaps in the sputtered coating, still have an effect. Thus, if the surface to measure is rough, the actually measured coating thickness is not the average height $(d)$, but a certain factor higher than $(d)$. Only if the roughness of the substrate and the coating are the same is this effect negligible. Gaps in the sputtered coating appear due to island growth (see Figure 19). 
When this happens, light is partially reflected on the sputtered island and partially on the coating. This might lead to deviations in the measured value of the coating thickness. Moreover, even this sputtered coating might show different growth behavior, which might again manipulate the results. Piegari and Masetti [59] followed that, in order to avoid deviations, the sputtered coating should be applied in a high vacuum at low condensation temperatures. However, the accuracy is reported to be approximately $1 \%$.

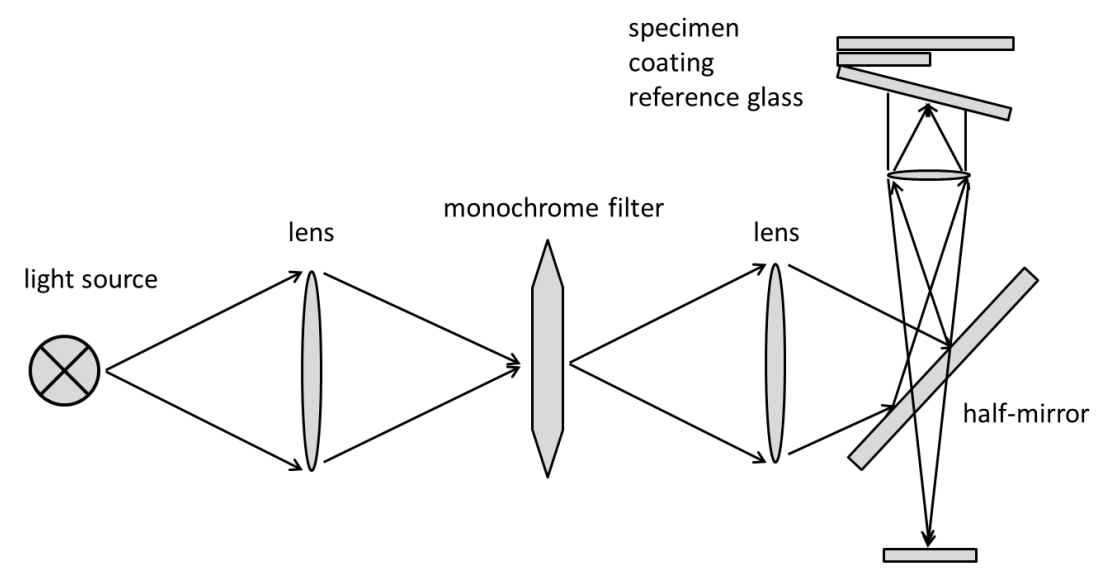

Figure 18. Set up for interference measurement.

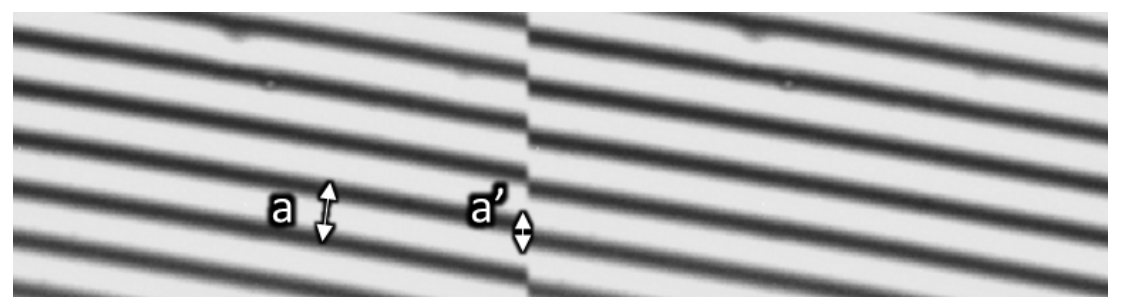

Figure 19. Microscopic image of interference bands.

\subsubsection{Electrical Surface Resistance}

\section{Electrical Surface Resistance: Theory}

Electrical resistivity $(R)$ is the property of a current carrying conductor to inhibit the current flow. It is inhibited by collisions with lattice defects and impurities as well as oscillations of the crystal lattice atoms [100]. It is defined as the relation of voltage $(U)$ to current $(I)$. The inverse value represents the conductivity $(G)$ (Equation (31)) [75]. The electrical resistivity depends on the geometry and material characteristics of the current carrying conductor. With the help of the specific electrical resistivity $(\rho)$, length $(l)$, width $(b)$ and thickness $(d)$ of the conductor, the expected resistivity $(R)$ can be calculated (Equation (32)). If length $(l)$ and width $(b)$ are equal, both can be deducted from the formula which leads to the value of the so called surface resistivity $\left(R_{\boldsymbol{\square}}\right)$ (Equation (33)). As this resistivity is measured in a squarish setup, it is often indexed with a small square $\left(R_{\square}\right)$. The advantage is now, that by using a defined construction (with $l=b$ ) for measuring the resistance, the coating thickness $(d)$ can easily be calculated from Equation (33).

$$
\begin{gathered}
R=\frac{U}{I} G=\frac{1}{R}=\frac{I}{U} \\
R=\rho \times \frac{l}{A}=\frac{\rho \times l}{d \times b} \\
R \square=\frac{\rho \times l}{d \times b}=\frac{\rho}{d}(\text { with } l=b)
\end{gathered}
$$


Pursuant to the Drude-Lorentz-Sommerfeld theory, the conductivity of metals is subjected to the density of the free electrons in the metal $(n)$, the electron charge $(e)$, the mean free path of the conducting electrons $(l)$, the effective mass of an electron $(m)$, and the average speed of free electrons $\left(v_{\mathrm{F}}\right)$, like in Equation (34). However, the mean free path $(a)$ is related to the amount of imperfections and defects as well as the structure of the conductor as electrons are scattered on these lattice imperfections [100]. Kinds of imperfections are revealed in [34]. For small amounts of impurities, the effective resistivity is a sum of the bulk resistivity $\left(\rho_{\mathrm{b}}(T)\right)$ in dependence of the temperature $(T)$ and the resistivity of the defects $\left(\rho_{\mathrm{d}}(c)\right)$ in dependence of the defect concentration $(c)$ [100]. According to Mattheissen's rule for thin metal coatings, an additional term for the scattering at the boundary surfaces $\left(\rho_{\mathrm{h}}(h)\right)$ can be added, which correlates with the thickness $(d)$ of the thin coating [100]:

$$
\begin{gathered}
\rho_{0}=\frac{m \times v_{\mathrm{F}}}{n \times e^{2} \times a} \\
\rho_{0}=\rho_{\mathrm{b}}(T)+\rho_{\mathrm{d}}(c)+\rho_{\mathrm{d}}(d)
\end{gathered}
$$

Electrical Surface Resistance: Method

In order to eliminate $(b)$ and $(l)$ from Equation (33), a defined geometry of the measured surface needs to be ensured where $b=l$. For accuracy reasons, usually 4 point set ups are used which are depicted in Figure 20. Therefore, electrodes might either be arranged in a linear or in a squarish way (van-der-Pauw method). In each case, the current is introduced between point (A) and (B) and the decrease in voltage is determined via (C) and (D).

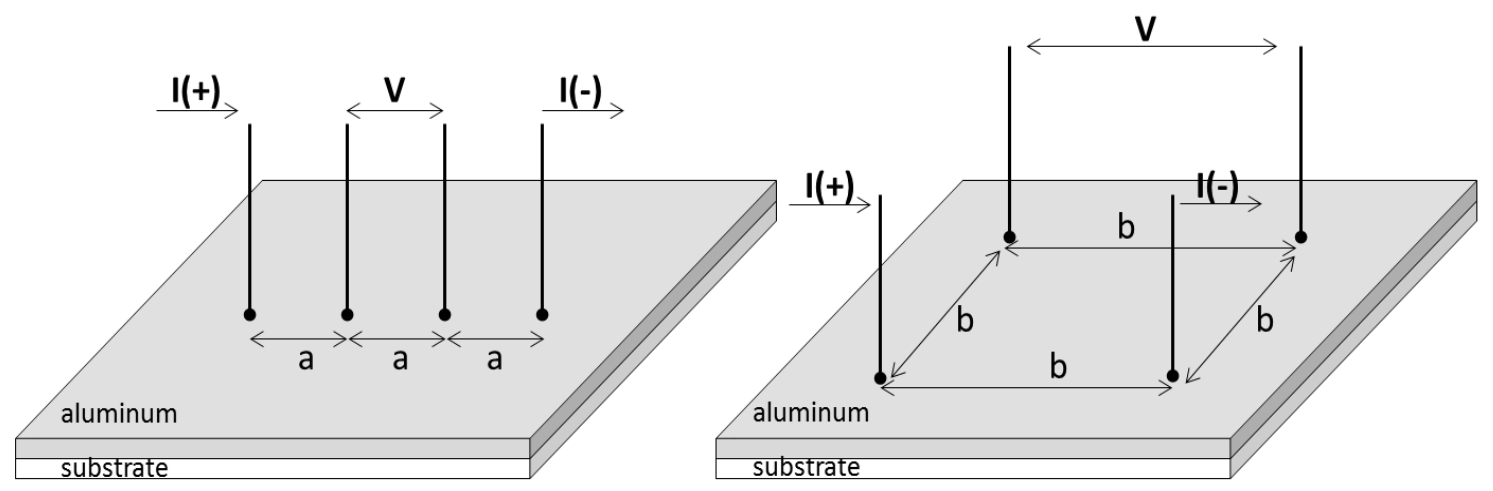

Figure 20. Common arrangements for measurement of surface resistance.

Electrical Surface Resistance: Practical Aspects and Analyses

Especially for nanometer thin coatings, the gravitational pressure of the tool might already cause cracks in the material. To reduce the influence of the pressure of the measurement setup on the thin coating, the electrodes are sometimes spring loaded. Moreover, oxide layers (which can have a resistivity 20 -fold higher than the pure metal) can increase the determined value. Once the surface resistivity $\left(R_{\mathbf{\square}}\right)$ is measured, the coating thickness $(h)$ can easily be calculated. However, some more effects should be taken into account, when interpreting this value.

Aluminum oxide has a resistivity of $10^{18}\left(\Omega \cdot \mathrm{mm}^{2}\right) / \mathrm{m}$, which is 20 -fold higher than aluminum. Consequently, the thickness of aluminum oxide is not captured in the measured value.

Another factor is the effect of electron scattering on surfaces and grain boundaries, of surface roughness and of island growth on electrical conductivity for different other metals such as copper, silver or gold were evaluated by [101-119] and fitted to models of Fuchs [120], Sondheimer [121], Soffer [122], Namba [107], Mayadas, and Shatzkes [123,124].

Rider and Foxon [125] quantified the dislocation density in cold-worked and partially annealed aluminum. They found that the dislocation resistivity was independent of dislocation density and 
arrangement. Additionally, Mayadas and Feder [126] measured the resistivity of thin aluminum coatings in the range of 700 to $10,000 \AA$ and modeled the effect of electron scattering on surfaces as well as on grain boundaries. However, the fitting of the curves to the Fuchs theory was not successful. However, Mayadas and Shatzkes [123] showed that if the grain size increases with coating thickness, then a distinct effect on the resistivity exists. In [124] the resistivity of a thin aluminum coating is modeled, taking into account the background scattering of phonons and point defects, grain boundaries, and scattering on external surfaces. The conclusions were that the effect of thickness on resistivity is due to the grain-boundary scattering and the Fuchs size effect. The grain-boundary reflection coefficient in aluminum was found to be $\approx 0.15$. Apart from that, in [127] results are presented, where the effect of pore size, its volume fraction, and direction on the electrical resistivity was measured, modeled, and simulated.

The methods limitation is mainly fixed by the set ups measurement range. Especially when aluminum coatings are thin and the distance between single atoms or clusters is large, no current can flow. Consequently, the resistivity of the aluminum coating is high and the measured value will principally be that of the substrate and therefore probably not detectable. This effect has been experimentally and theoretically investigated by $[103,106,128,129]$.

\subsubsection{Eddy Current Measurement}

Just like with the setup for the electrical surface resistance, the eddy current technology is used to measure the resistivity — or in this case the conductivity —of the aluminum surface. The eddy current measurement is extendable to the impedance spectroscopy by varying the inserted frequency of the current $(I)$, which allows for extracting some more information about Ohmic and capacitive resistivities (as e.g., in [130]).

\section{Eddy Current Measurement: Theory}

Just like surface resistance measurement, the eddy current measurement is an electrical method. However, it can be applied for non-destructive material testing, which is especially used for defining quality characteristics like coating thickness, resistivity, material homogeneity, and other physical changes in the material. By applying an alternating voltage (100 kHz to some $\mathrm{MHz}$ ) on the induction coil, an electromagnet field (primary field) is generated. If a conducting sample is placed in this electromagnetic field, eddy currents are triggered in the sample. The notation "eddy current" is based on the movement of the current carriers on circular paths. This eddy current then leads to a secondary electromagnetic field, which impinges on the primary field. This impingement can be measured and related to the thickness of the coating [65]. The basic physical principles are outlined in the following. However, the exact mathematical description of the interaction of coil and a flat metal sheet can be found in [131].

The aluminum coating is characterized by the thickness $(d)$, the electrical conductivity $(1 / R)$, and the magnetic permeability $\left(\mu_{\mathrm{r}}\right)$ [65]. When an alternating current passes a coil, this leads to the development of an electromagnetic field (Figure 21), defined by the magnetic flux density (B1) and electric flux density $(E)$, which leads to the movement of current carriers with the velocity $(v)$ in a flat metal sheet supposed to the field. The three vectors $(B),(E)$, and $(v)$ are perpendicular to each other (Lorentz rule) (Equation (38)) and lead to the circular movement of the current carriers in the aluminum (eddy current). The magnetic flux density $\left(B_{1}\right)$ is triggered depending on the electrical current $(I)$ passing through the coil, the length of the coil $(l)$, its coil number $(N)$, and the magnetic constant $\left(\mu_{0}\right)$ (Equation (36)). These eddy currents trigger a secondary magnetic field $\left(B_{2}\right)$, which is opposite directed and alters the primary field $\left(B_{1}\right)$. Pursuant to the rule of Lenz, the secondary field superimposes the first one and reduces it to the value of $\left(B_{1}{ }^{\prime}\right)$. The relation of $\left(B_{1}{ }^{\prime}\right)$ to $\left(B_{1}\right)$ is denoted as the permeability $\left(\mu_{\mathrm{r}}\right)$. In a nutshell, the eddy currents will be higher when the aluminum coating is thicker, and the inductance in the coil will be lower $[65,132,133]$. This energy loss consists of three parts: the hysteresis loss $\left(W_{\mathrm{h}}\right)$, the classical loss $\left(W_{\mathrm{cl}}\right)$, and the excess loss $\left(W_{\mathrm{exc}}\right)$ (see Equation (42)). 
Herein the classical loss $\left(W_{\mathrm{cl}}\right)$ depends on the thickness as in Equation (43). Here, $(\sigma)$ is the conductivity, $(d)$ is the material thickness, $\left(J_{p}\right)$ is the peak polarization, $(f)$ is the frequency, and $(\delta)$ is the material density [134].

$$
\begin{gathered}
B=\mu_{0} \times I \times \frac{N}{l} \\
F_{\mathrm{M}}=Q \times v \times B \\
F_{\mathrm{L}}=Q \times v \times B+Q \times E \\
\mu_{\mathrm{r}}=\frac{B}{B_{0}} \\
\mu=\mu_{0} \times \mu_{\mathrm{r}} \\
\mathrm{Z}=\frac{U_{\mathrm{eff}}}{I_{\mathrm{eff}}} \\
W=W_{\mathrm{h}}+W_{\mathrm{cl}}+W_{\mathrm{exc}} \\
W_{\mathrm{cl}}=\frac{\pi^{2}}{6} \times \frac{\sigma d^{2} J_{\mathrm{p}}^{2} f}{\delta}
\end{gathered}
$$

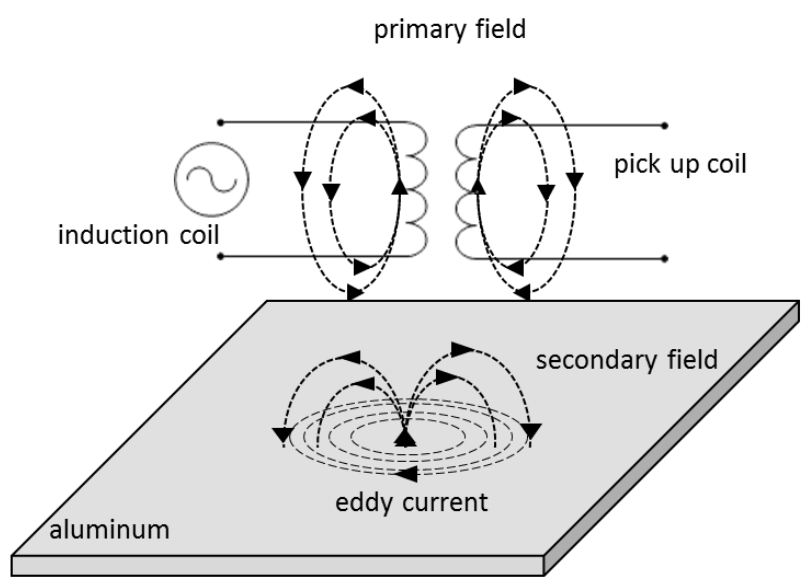

Figure 21. Schematic representation of eddy current (adapted from [133]).

\section{Eddy Current Measurement: Method}

Basically, two different methods are used for eddy current measurements: the surface and transmission technique. In the first case, the sending coil is also the receiving coil and the specimen is placed at a defined distance to it. In the second case, the specimen is placed between two coils: the first one triggers the electromagnetic field; in the second coil the electromagnetic field leads to a current in the coil. The second method has the advantage that misalignments as well as the distance between coil and specimen only have a minor effect on test results [135]. Various different methods and setups are reviewed in [136].

In order to reveal the shift of inductance, a circuit can be used, as in Figure 22. This consists of a power supply $\left(U_{0}\right)$, the coil with inductance $(L)$, the coils' resistivity $(r)$, a capacitor $(C)$, and an external resistor $(R)$. Because of the shift of energy between the coil and the capacitor, the circuit oscillates and shows a typical resonance frequency, which can be monitored via the LC circuit voltage $\left(U_{\mathrm{LC}}\right)$. When the sample is introduced to the system, the coils inductivity $(L)$ changes and the resonance voltage $\left(U_{\mathrm{LC}}\right)$ shifts away. The change of $\left(U_{\mathrm{LC}}\right)$ is amplified and related to the samples' surface resistivity $\left(R_{\mathbf{m}}\right)$. Further variations in the eddy current measurements are described in [130,131,135,137-141]. 


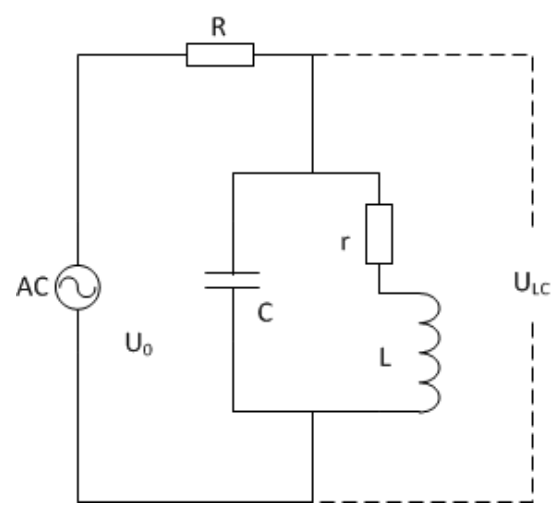

Figure 22. Resonant circuit used of eddy current measurements (adapted from [142]).

Eddy Current Measurement: Practical Aspects and Analyses

Once the surface resistance $\left(R_{\mathbf{\square}}\right)$ is measured, the material thickness $(d)$ can then be calculated from Equation (33). New systems exist, that automatically or semi-automatically measure the surface resistance in a raster of e.g., $1 \mathrm{~cm}$ squares. Although eddy current measurements area a rather punctual method, this offers the opportunity to gain an average value which characterizes a whole material area. In [143] simulations have been carried out that show a clear relationship between bulk resistivity of the specimens and the eddy current induced in the thin conductor metals. Measurement setups are available e.g., in the range of $0.001-3000 \Omega$ /sq, that equals of an ideal aluminum coating thickness of approximately $26 \mu \mathrm{m}-0.01 \mathrm{~nm}$ [133]. Just like in the electrical surface resistance measurement, aluminum oxide is not captured in the measured value because of the extremely high resistivity.

However, several factors might affect the results. Heuer and Hillmann [139] stated, that subjected to the frequency, the depth where eddy currents are triggered might vary. Therefore, for thicker materials, a lower frequency is necessary to ensure the full penetration of the material.

$\mathrm{Qu}, \mathrm{Zhao}$ [142] varied the coil resistance, its capacity, and induction in the LC circuit and found that, by reducing the resistance by using multi strand of wires for the coil the sensitivity increases. The maximum sensitivity reached was $2 \mathrm{mV} / \mathrm{nm}$. The importance of sensitivity was also emphasized by Angani, Ramos [141]. Moulder, Uzal [140] determined the effect of the coil size to specimen thickness ratio on the sensitivity of the instrument. They found that for thin specimens only one feature (thickness or conductivity) can be measured when the other one is known. This effect is also comprehensively explained in [135], where a solution is presented as to avoid this problem by choosing the right frequency. Similar to Moulder, Uzal [140], Rajotte [138] also recommended, that the specimen should be at least 1.5 times larger than the outside diameter of the spiral coil.

Hillmann, Klein [135] evaluated the effect of sensor-to-sensor distances and material thickness on the deviation from expected values and found a non-linear behavior. The deviation was small (approximately 0.25 to $1.5 \mathrm{~nm}$ ) and showed a further decrease for thicknesses below $20 \mathrm{~nm}$. However, the deviation was much higher (approximately 0.5 to $4.0 \mathrm{~nm}$ ) but still showed a decrease for thicknesses of $\geq 50 \mathrm{~nm}$. A smaller distance between the two sensors $(6 \mathrm{~cm}, 4 \mathrm{~cm}$ and $2 \mathrm{~cm}$ were tested) seemed to reduce the deviation.

Heuer, Hillmann [139] and Hillmann, Klein [135] even stated that the kind of material in mono and multilayers, the depth profile, thicknesses, and hardnesses as well as microstructure properties can be revealed. However, they were partially working in a thickness range of several micrometers and it is not mentioned which method was used to apply the coating. Concerning the differentiation of materials, Hillmann, Klein [135] emphasized the importance of choosing the right frequency, in order to properly distinguish between different materials with different conductivities and thicknesses. Angani, Ramos [141] proposed using this method to evaluate the corrosion of metals. 


\section{Methods Overview and Conclusions}

As illustrated before, each method has its challenges when it comes to the interpretation of the measured values. No measurement is the "wrong" or the "right" one, but they need to be interpreted based on the characteristic that is actually acquired. Only in accordance with the scope of application, can the "most suitable" system be chosen. Table 1 gives an overview that provides indications for choosing the most suitable method for different purposes. The indications are denoted as follows.

Table 1. Overview over methods.

\begin{tabular}{|c|c|c|c|c|c|c|c|c|}
\hline \multirow[t]{2}{*}{ Characteristic } & \multicolumn{2}{|c|}{ Mass Thickness } & \multirow{2}{*}{$\begin{array}{c}\text { Geometrical } \\
\text { Thickness }\end{array}$} & \multicolumn{5}{|c|}{ Property Thickness } \\
\hline & QCM & ICP-MS & & $\begin{array}{l}\text { Eddy Current } \\
\text { Measurement }\end{array}$ & $\begin{array}{c}\text { Electrical } \\
\text { Resistivity } \\
\text { Linear }\end{array}$ & $\begin{array}{l}\text { Electrical } \\
\text { Resistivity } \\
\text { Squarish }\end{array}$ & $\begin{array}{l}\text { Optical } \\
\text { Density }\end{array}$ & Interference \\
\hline $\begin{array}{l}\text { Measurement } \\
\text { range }\end{array}$ & ++ & +++ & ++ & +++ & +++ & +++ & + & ++ \\
\hline Non destructive & $\checkmark$ & $x$ & $x$ & $\checkmark$ & $x$ & $x$ & $\checkmark$ & $x$ \\
\hline $\begin{array}{l}\text { Punctual } \\
\text { measurement }\end{array}$ & $(\checkmark)$ & $x$ & $\checkmark$ & $\checkmark$ & $x$ & $x$ & $\checkmark$ & $\checkmark$ \\
\hline $\begin{array}{l}\text { Measurement } \\
\text { within multilayer } \\
\text { is possible }\end{array}$ & $x$ & $\checkmark$ & $(\checkmark)$ & $\checkmark$ & $x$ & $x$ & $x$ & $x$ \\
\hline $\begin{array}{l}\text { Is only metallic } \\
\text { aluminum } \\
\text { detected? }\end{array}$ & $\checkmark$ & $x$ & $x$ & $\checkmark$ & $\checkmark$ & $\checkmark$ & $\checkmark$ & $\checkmark$ \\
\hline $\begin{array}{l}\text { Usable as inline } \\
\text { measurement }\end{array}$ & $\checkmark$ & $x$ & $x$ & $\checkmark$ & $x$ & $x$ & $\checkmark$ & $x$ \\
\hline Financial invest & + & +++ & +++ & ++ & + & + & + & ++ \\
\hline
\end{tabular}

From this overview it can be concluded, that a higher financial investment does not necessarily lead to shorter measuring times or higher measurement ranges. Whereas ICP-MS, AFM, and interference seem to be more interesting methods for science related questions, especially QCM, eddy current, electrical resistivity, and optical density are commonly used in packaging material producing industries. QCM and optical density are widely used as inline measurement method, as they are also non-destructive.

When it comes to the correlation of thickness values with barrier effects against water vapor and oxygen, the awareness about the subdivision into mass, geometrical, and property thickness is useful. As permeation appears mainly through areas where the aluminum coating is not yet closed or is defective, the interpretation of measured and derived thickness values is critical.

For the calculation of mass thickness measurements, it is assumed that all the aluminum in the sample is arranged in a perfectly crystalline manner on the substrate surface. It is not taken into account that there might be defects or irregularities in the atomic lattice or aluminum that reacted to aluminum oxide and might influence the gas barrier.

In contrast to that, the geometrical measurement based on AFM is a very punctual measurement. The measured thickness consists of both the pure aluminum and also of aluminum oxide. Here one needs to be aware that the molar volume of aluminum oxide is higher (values depending on the exact composition) than that of pure aluminum. Additionally, the measurement should be repeated at different areas of the sample as it cannot be excluded that one measurement is done on a defect or an area with extraordinarily high or thin aluminum coverage. 
As the name suggests, property thickness measurements measure a certain property of the aluminum, the thickness of which is then calculated based on the assumption that the nanometer thin coating behaves like an ideal bulk material. However, it is known, that nanometer materials behave differently from bulk material. Imagine a thick coating, full of pores and defects. These pores and defects might lead to increased electrical resistivity. Thus, a thickness would be calculated, that is thinner than it actually is (compare Equation (33)). For the case of optical density, an increasing relative amount of aluminum oxide decreases the measured value for the optical density. The amount of aluminum oxide is in turn affected by the residual oxygen in the recipient.

From this overview it becomes obvious, that the thickness can be measured rather quickly; however, a full characterization of the coating can only be done by the combination of the above mentioned methods.

Acknowledgments: This work was supported by the German Research Foundation (DFG) and the Technical University of Munich (TUM) in the framework of the Open Access Publishing Program. Therefore the authors thank the DFG and TUM for their support. Moreover, the authors thank Horst-Christian Langowski and Florian Höflsauer for their support.

Author Contributions: Martina Lindner wrote the manuscript and was in charge of the overall outline and editing of the manuscript. She was involved in the revision and completion of the work. Markus Schmid contributed to the outline as well as to the revision, completion, and editing of the manuscript.

Conflicts of Interest: The authors declare no conflict of interest.

\section{References}

1. Bichler, C.; Langowski, H.C.; Moosheimer, U.; Bischoff, M. Transparente Aufdampfschichten aus Oxiden von $\mathrm{Si}, \mathrm{Al}$ und Mg für Barrierepackstoffe. Available online: https://www.mysciencework.com/publication/ show/430561f397d6f9ad469136be1369ee3b (accessed on 29 December 2016).

2. Pilchik, R. Pharmaceutical blister packaging, Part I. Pharm. Technol. 2000, 24, 68-78.

3. Dean, D.A.; Evans, E.R.; Hall, I.H. Pharmaceutical Packaging Technology; Taylor \& Francis: London, UK, 2005.

4. Huang, C.C.; Ma, H.W. A multidimensional environmental evaluation of packaging materials. Sci. Total Environ. 2004, 324, 161-172. [CrossRef] [PubMed]

5. Seshan, K. Handbook of Thin Film Deposition Processes and Techniques; William Andrew: Norwich, NY, USA, 2002.

6. Mattox, D.M. Physical vapor deposition (PVD) processes. Metal Finish. 2001, 99, 409-423. [CrossRef]

7. Pierson, H.O. Handbook of Chemical Vapor Deposition: Principles, Technology and Applications; William Andrew: Norwich, NY, USA, 1999.

8. Leskelä, M.; Ritala, M. Atomic layer deposition (ALD): From precursors to thin film structures. Thin Solid Films 2002, 409, 138-146. [CrossRef]

9. Hirvikorpi, T.; Vähä-Nissi, M.; Mustonen, T.; Harlin, A.; Iiskola, E.; Karppinen, M. Thin inorganic barrier coatings for packaging materials. In Proceedings of the PLACE 2010 Conference, Albuquerque, NM, USA, 18-21 April 2010.

10. Mackenzie, J.D.; Bescher, E.P. Physical properties of sol-gel coatings. J. Sol-Gel Sci. Technol. 2000, 19, 23-29. [CrossRef]

11. Logothetidis, S.; Laskarakis, A.; Georgiou, D.; Amberg-Schwab, S.; Weber, U.; Noller, K.; Schmidt, M.; Kuecuekpinar-Niarchos, E.; Lohwasser, W. Ultra high barrier materials for encapsulation of flexible organic electronics. Eur. Phys. J. Appl. Phys. 2010, 51, 33203. [CrossRef]

12. Noller, K.; Mikula, M.; Amberg-Schwab, S.; Weber, U. Multilayer coatings for flexible high-barrier materials. Open Phys. 2009, 7, 371-378.

13. Brinker, C.J.; Frye, G.C.; Hurd, A.J.; Ashley, C.S. Fundamentals of sol-gel dip coating. Thin Solid Films 1991, 201, 97-108. [CrossRef]

14. Schultrich, B. Physikalische dampfphasenabscheidung: Bedampfen. In Proceedings of the Surface Engineering und Nanotechnologie SENT, Dresden, Germany, 5-7 December 2006.

15. Bishop, C.A. Vacuum Deposition onto Webs, Films and Foils, 2nd ed.; Elsevier: Amsterdam, The Netherlands, 2011.

16. Mondolfo, L.F. Aluminum Alloys: Structure and Properties; Elsevier: Amsterdam, The Netherlands, 2013.

17. Ans, J.; Lax, E.; Synowietz, C. Taschenbuch für Chemiker und Physiker; Springer: Berlin/Heidelberg, Germany, 1967. 
18. Hatch, J.E.; Association, A.; Metals, A.S. Aluminum: Properties and Physical Metallurgy; American Society for Metals: Geauga County, OH, USA, 1984.

19. Kaßmann, M. Grundlagen der Verpackung: Leitfaden für die Fächerübergreifende Verpackungsausbildung; Beuth Verlag: Berlin, Germany, 2014.

20. Iwakura, K.; Wang, Y.D.; Cakmak, M. Effect of Biaxial Stretching on Thickness Uniformity and Surface Roughness of PET and PPS Films. Int. Polym. Process. 1992, 7, 327-333. [CrossRef]

21. Cakmak, M.; Wang, Y.; Simhambhatla, M. Processing characteristics, structure development, and properties of uni and biaxially stretched poly (ethylene 2,6 naphthalate)(PEN) films. Polym. Eng. Sci. 1990, 30, 721-733. [CrossRef]

22. Lin, Y.J.; Dias, P.; Chum, S.; Hiltner, A.; Baer, E. Surface roughness and light transmission of biaxially oriented polypropylene films. Polym. Eng. Sci. 2007, 47, 1658-1665. [CrossRef]

23. Müller, K.; Schönweitz, C.; Langowski, H.C. Thin Laminate Films for Barrier Packaging ApplicationInfluence of Down Gauging and Substrate Surface Properties on the Permeation Properties. Packag. Technol. Sci. 2012, 25, 137-148. [CrossRef]

24. Utz, H. Barriereeigenschaften Aluminiumbedampfter Kunststoffolien. Ph.D. Thesis, Technische Universität, Fakultät für Brauwesen, Lebensmitteltechnologie und Milchwissenschaft, Berlin, Germany, 1995. (In German)

25. Kim, C.; Goring, D. Surface morphology of polyethylene after treatment in a corona discharge. J. Appl. Polym. Sci. 1971, 15, 1357-1364. [CrossRef]

26. Neugebauer, A. Condensation, nucleation, and growth of thin films. In Handbook of Thin Film Technology; Maissel, L.I., Glang, R., Eds.; McGraw-Hill: New York, NY, USA, 1970.

27. Haefer, R.A. Oberflüchen- und Dünnschicht-Technologie; Springer: Berlin, Germany, 1987.

28. Jacobs, K. H. Frey, G. Kienel. Dünnschichttechnologie. VDI-Verlag GmbH, Düsseldorf 1987. 691 + XVIII pages, numerous figures and tables, 395.00 DM, ISBN 3-18-400670-0. Cryst. Res. Technol. 1989, 24, 1232. [CrossRef]

29. Vook, R.W. Structure and growth of thin films. Int. Met. Rev. 1982, 27, 209-245. [CrossRef]

30. Reichelt, K.; Jiang, X. The preparation of thin films by physical vapour deposition methods. Thin Solid Films 1990, 191, 91-126. [CrossRef]

31. Kern, R.; Metois, G.L. Basic mechanisms in the early stage of epitaxy. Curr. Top. Mater. Sci. 1979, 3, $135-419$.

32. Stoyanov, S. Nucleation theory for high and low supersaturations. Curr. Top. Mater. Sci. 1979, 3, 421-462.

33. Bravais, A. Abhandlung über Die Systeme von Regelmässig auf Einer Ebene Oder Raum Vertheilten Punkten; Wilhelm Engelmann: Leipzig, Germany, 1897. (In German)

34. Gottstein, G. Materialwissenschaft und Werkstofftechnik: Physikalische Grundlagen; Springer: Berlin, Germany, 2014.

35. Weitze, M.D.; Berger, C. Strukturen und Eigenschaften. In Werkstoffe: Unsichtbar, Aber Unverzichtbar; Springer: Berlin, Germany, 2013; pp. 9-66.

36. Bollmann, W. Crystal Defects and Crystalline Interfaces; Springer Science \& Business Media: Berlin, Germany, 2012.

37. Miesbauer, O.; Schmidt, M.; Langowski, H.C. Stofftransport durch Schichtsysteme aus Polymeren und dünnen anorganischen Schichten. Vak. Forsch. Prax. 2008, 20, 32-40. [CrossRef]

38. Barker, C.P.; Kochem, K.-H.; Revell, K.M.; Kelly, R.S.A.; Badyal, J.P.S. The Interfacial Chemistry of Metal Oxide Coated and Nanocomposite Coated Polymer Films. Thin Solid Films 1995, 257, 77-82. [CrossRef]

39. Copeland, N.J.; Astbury, R. Evaporated aluminium on polyester: Optical, Electrical, and Barrier Properties as a Function of Thickness and Time (Part I). In Proceedings of the AIMCAL Technical Conference, Myrtle Beach, SC, USA, 14 October 2010.

40. Hass, G.; Scott, N.W. On the structure and properties of some metal and metal oxide films. J. Phys. Radium 1950, 11, 394-402. [CrossRef]

41. McClure, D.; Struller, C.; Langowski, H.C. Evaporated Aluminium on Polypropylene: Oxide-Layer Thickness as a Function of Oxygen Plasma-Treatment Level. Available online: http:/ /www.aimcal.org/uploads/4/6/ 6/9/46695933/mcclure_abs.pdf (accessed on 29 December 2016).

42. McClure, D.J.; Copeland, N. Evaporated Aluminium on Polyester: Optical, Electrical, and Barrier Properties as a Function of Thickness and Time (Part II). Available online: http://dnn.convertingquarterly.com/magazine/ matteucci-awards/id/2420/evaporated-aluminum-on-polyester-optical-electrical-and-barrier-propertiesas-a-function-of-thickness-and-time-part-1.aspx (accessed on 29 December 2016).

43. Menges, G. Werkstoffkunde der Kunststoffe; Walter de Gruyter: Berlin, Germany, 1971; Volume 2620. 
44. Prins, W.; Hermans, J.J. Theory of Permeation through Metal Coated Polymer Films. J. Phys. Chem. 1959, 63, 716-720. [CrossRef]

45. Langowski, H.C. Stofftransport durch polymere und anorganische Schichten Transport of Substances through Polymeric and Inorganic Layers. Vak. Forsch. Prax. 2005, 17, 6-13. [CrossRef]

46. Langowski, H.C.; Utz, H. Dünne anorganische Schichten für Barrierepackstoffe. Int. Z. Lebensm. Technol. Mark. Verpack. Anal. 2002, 9, 522.

47. Roberts, A.P.; Henry, B.M.; Sutton, A.P.; Grovenor, C.R.; Briggs, G.A.; Miyamoto, T.; Kano, M.; Tsukahara, Y.; Yanaka, M. Gas permeation in silicon oxide/polymer (SiOx/PET) barrier films: Role of oxide lattice, nano-defects and macrodefects. J. Membr. Sci. 2002, 208, 75-88. [CrossRef]

48. Lohwasser, W. Not only for packaging. In Proceedings of the 43rd Annual Technical Conference of the Society of Vacuum Coaters, Denver, CO, USA, 23-28 April 2000.

49. Hanika, M.; Langowski, H.C.; Moosheimer, U.; Peukert, W. Inorganic layers on polymeric films-Influence of defects and morphology on barrier properties. Chem. Eng. Technol. 2003, 26, 605-614. [CrossRef]

50. Hanika, M. Zur Permeation Durch Aluminiumbedampfte Polypropylen-und Polyethylenterephtalatfolien. Ph.D. Thesis, Technical University of Munich, Munich, Germany, 2004.

51. Mueller, K.; Weisser, H. Numerical simulation of permeation through vacuum-coated laminate films. Packag. Technol. Sci. 2002, 15, 29-36. [CrossRef]

52. Rossi, G.; Nulman, M. Effect of local flaws in polymeric permeation reducing barriers. J. Appl. Phys. 1993, 74, 5471-5475. [CrossRef]

53. Jamieson, E.H.H.; Windle, A.H. Structure and oxygen-barrier properties of metallized polymer film. J. Mater. Sci. 1983, 18, 64-80. [CrossRef]

54. Bugnicourt, E.; Kehoe, T.; Latorre, M.; Serrano, C.; Philippe, S.; Schmid, M. Recent Prospects in the Inline Monitoring of Nanocomposites and Nanocoatings by Optical Technologies. Nanomaterials 2016, 6, 150. [CrossRef]

55. Utz, H. Barriereeigenschaften Aluminiumbedampfter Kunststofffolien. Ph.D. Thesis, Technical University of Munich, Munich, Germany, 1995.

56. Kääriäinen, T.O.; Maydannik, P.; Cameron, D.C.; Lahtinen, K.; Johansson, P.; Kuusipalo, J. Atomic layer deposition on polymer based flexible packaging materials: Growth characteristics and diffusion barrier properties. Thin Solid Films 2011, 519, 3146-3154. [CrossRef]

57. McCrackin, F.L.; Passaglia, E.; Stromberg, R.R.; Steinberg, H.L. Measurement of the thickness and refractive index of very thin films and the optical properties of surfaces by ellipsometry. J. Res. Natl. Bur. Stand. Phys. Chem. A 1963, 67, 363-377. [CrossRef]

58. Chatham, H. Oxygen diffusion barrier properties of transparent oxide coatings on polymeric substrates. Surf. Coat. Technol. 1996, 78, 1-9. [CrossRef]

59. Piegari, A.; Masetti, E. Thin film thickness measurement: A comparison of various techniques. Thin Solid Films 1985, 124, 249-257. [CrossRef]

60. Pulker, H.K. Thickness measurement, rate control and automation in thin film coating technology. In Proceedings of the 1983 International Techincal Conference, Geneva, Switzerland, 18 April 1983.

61. Mattox, D.M. Film characterization and some basic film properties. In Handbook of Physical Vapor Deposition (PVD) Processing; Mattox, D.M., Ed.; William Andrew Publishing: Westwood, NJ, USA, 1998; pp. 569-615.

62. Martin, P.M. Handbook of Deposition Technologies for Films and Coatings: Science, Applications and Technology; Elsevier: Amsterdam, The Netherlands, 2009.

63. Juzeliūnas, E. Quartz crystal microgravimetry-fifty years of application and new challenges. Chemija 2009, $20,218-225$.

64. Zeitvogl, J. Quarzkristallmikrowaage-QCM. Ph.D. Thesis, University of Erlangen-Nuremberg, Erlangen, Germany, 2009.

65. Frey, H.; Khan, H.R. Handbook of Thin Film Technology; Springer: Berlin, Germany, 2010.

66. Höpfner, M. Untersuchungen zur Anwendbarkeit der Quarzmikrowaage für Pharmazeutisch Analytische Fragestellungen. Ph.D. Thesis, Martin Luther University of Halle-Wittenberg, Halle, Germany, 2005.

67. MacLeod, H.A. Thin-Film Optical Filters, 3rd ed.; CRC Press: Cleveland, OH, USA, 2001.

68. Sauerbrey, G. Verwendung von Schwingquarzen zur Wägung dünner Schichten und zur Mikrowägung. Z. Phys. 1959, 155, 206-222. [CrossRef] 
69. Lu, C.; Czanderna, A.W. Applications of Piezoelectric Quartz Crystal Microbalances; Elsevier: Amsterdam, The Netherlands, 2012.

70. Thomas, R. Practical Guide to ICP-MS: A Tutorial for Beginners, 2nd ed.; Taylor \& Francis: London, UK, 2008.

71. De Hoffmann, E.; Stroobant, V. Mass Spectrometry: Principles and Applications; Wiley: New York, NY, USA, 2007.

72. Zoorob, G.K.; McKiernan, J.W.; Caruso, J.A. ICP-MS for elemental speciation studies. Microchim. Acta 1998, 128, 145-168. [CrossRef]

73. Broekaert, J.A.C. ICP-Massenspektrometrie. In Analytiker-Taschenbuch; Günzler, H., Bahadir, A.M., Danzer, K., Engewald, W., Fresenius, W., Galensa, R., Huber, W., Linscheid, M., Schwedt, G., Tölg, G., Eds.; Springer: Berlin/Heidelberg, Germany, 1988; pp. 127-163.

74. May, T.W.; Wiedmeyer, R.H. A table of polyatomic interferences in ICP-MS. At. Spectrosc. 1998, 19, $150-155$.

75. Eaton, P.; West, P. Atomic Force Microscopy; Oxford University Press: Oxford, UK, 2010.

76. Voigtlaender, B. Scanning Probe Microscopy: Atomic Force Microscopy and Scanning Tunneling Microscopy; Springer: Berlin/Heidelberg, Germany, 2015.

77. Schieferdecker, H.G. Bestimmung Mechanischer Eigenschaften von Polymeren Mittels Rasterkraftmikroskopie; Fakultät für Naturwissenschaften, Universität Ulm: Ulm, Germany, 2005.

78. Meyer, G.; Amer, N.M. Simultaneous measurement of lateral and normal forces with an optical-beamdeflection atomic force microscope. Appl. Phys. Lett. 1990, 57, 2089-2091. [CrossRef]

79. Stenzel, O. The Physics of Thin Film Optical Spectra; Springer: Berlin, Germany, 2005.

80. Bubert, H.; Rivière, J.C.; Arlinghaus, H.F.; Hutter, H.; Jenett, H.; Bauer, P.; Palmetshofer, L.; Fabry, L.; Pahlke, S.; Quentmeier, A.; et al. Surface and Thin-Film Analysis; Wiley Online Library: New York, NY, USA, 2002.

81. Hertlein, J. Untersuchungen über Veränderungen der Barriereeigenschaften Metallisierter Kunststoffolien Beim Maschinellen Verarbeiten; Utz, Wiss: München, Germany, 1998.

82. Miller, D.A. Optical Properties of Solid Thin Films by Spectroscopic Reflectometry and Spectroscopic Ellipsometry; ProQuest: Ann Arbor, MI, USA, 2008.

83. Weiss, J. Einflussfaktoren auf die Barriereeigenschaften metallisierter Folien. Verpak. Rundsch. 1993, 44, $23-28$.

84. Anna, C.; Cosslett, V.E. The optical density and thickness of evaporated carbon films. Br. J. Appl. Phys. 1957, 8, 374-376.

85. Deb, S.K. Optical and photoelectric properties and colour centres in thin films of tungsten oxide. Philos. Mag. 1973, 27, 801-822. [CrossRef]

86. Johnson, P.B.; Christy, R.W. Optical Constants of the Noble Metals. Phys. Rev. B 1972, 6, 4370-4379. [CrossRef]

87. Agar, A.W. The measurement of the thickness of thin carbon films. Br. J. Appl. Phys. 1957, 8, 35-36. [CrossRef]

88. Moss, T.S. Optical Properties of Tellurium in the Infra-Red. Proc. Phys. Soc. Sec. B 1952, 65, 62-66. [CrossRef]

89. Lehmuskero, A.; Kuittinen, M.; Vahimaa, P. Refractive index and extinction coefficient dependence of thin $\mathrm{Al}$ and Ir films on deposition technique and thickness. Opt. Express 2007, 15, 10744-10752. [CrossRef] [PubMed]

90. Hass, G.; Waylonis, J.E. Optical constants and reflectance and transmittance of evaporated aluminum in the visible and ultraviolet. JOSA 1961, 51, 719-722. [CrossRef]

91. Schulz, L.G. The Optical Constants of Silver, Gold, Copper, and Aluminum. I. The Absorption Coefficient $k$. J. Opt. Soc. Am. 1954, 44, 357-362. [CrossRef]

92. Heavens, O.S. Optical properties of thin films. Rep. Prog. Phys. 1960, 23, 1-65. [CrossRef]

93. McMillan, G.K.; Considine, D. Process/Industrial Instruments and Controls Handbook, 5th ed.; McGraw-Hill: New York, NY, USA, 1999.

94. Pulker, H.K. Einfaches Interferenz-Wechselobjektiv für Mikroskope zur Dickenmessung nach Fizeau-Tolansky. Naturwissenschaften 1966, 53, 224. [CrossRef] [PubMed]

95. Hanszen, K.J. Der Einfluss von Strukturunregelmässigkeiten beim Zusammenwachsen zweier Aufdampfschichten auf das Schichtdickenmessverfahren mit Hilfe von Vielstrahl-Interferenzen. Thin Solid Films 1968, 2, 509-528. [CrossRef]

96. Großes Interferenzmikroskop. In Vertriebsabteilung Feinmessgeräte; Carl Zeiss Jena, Ed.; Druckerei Fortschritt: Jena, Germany, 1965.

97. Tippmann, H.; Schawohl, J.; Kups, T. Schichtdickenmessung; TU Ilmenau-Fakultät für Elektrotechnik und Informationstechnik Institut für Werkstofftechnik: Ilmenau, Germany, 2013.

98. Hammer, A.; Hammer, H.; Hammer, K. Physikalische Formeln und Tabellen; Lindauer: Munich, Germany, 1994.

99. Pitka, R. Physik: Der Grundkurs; Harri Deutsch Verlag: Frankfurt am Main, Germany, 1999. 
100. Zhigal'skii, G.P.; Jones, B.K. The Physical Properties of Thin Metal Films; CRC Press: Cleveland, OH, USA, 2003; Volume 13.

101. Liu, H.D.; Zhao, Y.P.; Ramanath, G.; Murarka, S.P.; Wang, G.C. Thickness dependent electrical resistivity of ultrathin (<40 nm) Cu films. Thin Solid Films 2001, 384, 151-156.

102. Philipp, M. Electrical Transport and Scattering Mechanisms in Thin Silver Films for Thermally Insulating Glazing. Available online: http://www.qucosa.de/fileadmin/data/qucosa/documents/7092/Dissertation_ Martin_Philipp.pdf (accessed on 29 December 2016).

103. Hoffmann, H.; Vancea, J. Critical-Assessment of Thickness-Dependent Conductivity of Thin Metal-Films. Thin Solid Films 1981, 85, 147-167. [CrossRef]

104. Leung, K.M. Electrical resistivity of metallic thin films with rough surfaces. Phys. Rev. B 1984, 30, 647-658. [CrossRef]

105. Ke, Y.; Zahid, F.; Timoshevskii, V.; Xia, K.; Gall, D.; Guo, H. Resistivity of thin Cu films with surface roughness. Phys. Rev. B 2009, 79, 155406. [CrossRef]

106. Borziak, P.G.; Kulyupin, Y.A.; Nepijko, S.A.; Shamonya, V.G. Electrical conductivity and electron emission from discontinuous metal films of homogeneous structure. Thin Solid Films 1980, 76, 359-378. [CrossRef]

107. Namba, Y. Resistivity and Temperature Coefficient of Thin Metal Films with Rough Surface. Jpn. J. Appl. Phys. 1970, 9, 1326-1329. [CrossRef]

108. Darevskii, A.S.; Zhdan, A.G. Real structure and electrical conductivity of island films of metals. Sov. Microelectron. 1978, 7, 356-359.

109. Bassewitz, A.V. Der Einfluß der Unterlage auf die Struktur und Leitfähigkeit metallischer Aufdampfschichten. Z. Phys. 1967, 201, 350-367. [CrossRef]

110. Jannesar, M.; Jafari, G.R.; Farahani, S.V.; Moradi, S. Thin film thickness measurement by the conductivity theory in the framework of born approximation. Thin Solid Films 2014, 562, 372-376. [CrossRef]

111. Palasantzas, G.; Zhao, Y.P.; Wang, G.C.; Lu, T.M.; Barnas, J.; De Hosson, J.T. Electrical conductivity and thin-film growth dynamics. Phys. Rev. B 2000, 61, 11109. [CrossRef]

112. Munoz, R.C.; Finger, R.; Arenas, C.; Kremer, G.; Moraga, L. Surface-induced resistivity of thin metallic films bounded by a rough fractal surface. Phys. Rev. B 2002, 66, 205401. [CrossRef]

113. Timalsina, Y.P.; Horning, A.; Spivey, R.F.; Lewis, K.M.; Kuan, T.S.; Wang, G.C.; Lu, T.M. Effects of nanoscale surface roughness on the resistivity of ultrathin epitaxial copper films. Nanotechnology 2015, 26, 075704. [CrossRef] [PubMed]

114. Ketenoğlu, D.; Ünal, B. Influence of surface roughness on the electrical conductivity of semiconducting thin films. Phys. A Stat. Mech. Appl. 2013, 392, 3008-3017. [CrossRef]

115. Arenas, C.; Henriquez, R.; Moraga, L.; Muñoz, E.; Munoz, R.C. The effect of electron scattering from disordered grain boundaries on the resistivity of metallic nanostructures. Appl. Surf. Sci. 2015, 329, 184-196. [CrossRef]

116. Lim, J.W.; Mimura, K.; Isshiki, M. Thickness dependence of resistivity for Cu films deposited by ion beam deposition. Appl. Surf. Sci. 2003, 217, 95-99. [CrossRef]

117. Zhang, W.; Brongersma, S.H.; Richard, O.; Brijs, B.; Palmans, R.; Froyen, L.; Maex, K. Influence of the electron mean free path on the resistivity of thin metal films. Microelectron. Eng. 2004, 76, 146-152. [CrossRef]

118. Camacho, J.M.; Oliva, A.I. Surface and grain boundary contributions in the electrical resistivity of metallic nanofilms. Thin Solid Films 2006, 515, 1881-1885. [CrossRef]

119. Camacho, J.M.; Oliva, A.I. Morphology and electrical resistivity of metallic nanostructures. Microelectron. J. 2005, 36, 555-558. [CrossRef]

120. Fuchs, K. The conductivity of thin metallic films according to the electron theory of metals. Math. Proc. Camb. Philos. Soc. 1938, 34, 100-108. [CrossRef]

121. Sondheimer, E.H. The mean free path of electrons in metals. Adv. Phys. 1952, 1, 1-42. [CrossRef]

122. Soffer, S.B. Statistical Model for the Size Effect in Electrical Conduction. J. Appl. Phys. 1967, 38, $1710-1715$. [CrossRef]

123. Mayadas, A.F.; Shatzkes, M.; Janak, J.F. Electrical resistivity model for polycrystalline films: The case of specular reflection at external surfaces. Appl. Phys. Lett. 1969, 14, 345-347. [CrossRef]

124. Mayadas, A.F.; Shatzkes, M. Electrical-Resistivity Model for Polycrystalline Films: The Case of Arbitrary Reflection at External Surfaces. Phys. Rev. B 1970, 1, 1382-1389. [CrossRef] 
125. Rider, J.G.; Foxon, C.T.B. An experimental determination of electrical resistivity of dislocations in aluminium. Philos. Mag. 1966, 13, 289-303. [CrossRef]

126. Mayadas, A.F.; Feder, R.; Rosenberg, R. Resistivity and structure of evaporated aluminum films. J. Vac. Sci. Technol. 1969, 6, 690-693. [CrossRef]

127. Nakajima, H. Porous Metals with Directional Pores; Springer: Berlin, Germany, 2013.

128. Lux, F. Models proposed to explain the electrical conductivity of mixtures made of conductive and insulating materials. J. Mater. Sci. 1993, 28, 285-301. [CrossRef]

129. Siegel, A.C.; Phillips, S.T.; Dickey, M.D.; Lu, N.; Suo, Z.; Whitesides, G.M. Foldable printed circuit boards on paper substrates. Adv. Funct. Mater. 2010, 20, 28-35. [CrossRef]

130. Parfenov, E.V.; Yerokhin, A.L.; Matthews, A. Impedance spectroscopy characterisation of PEO process and coatings on aluminium. Thin Solid Films 2007, 516, 428-432. [CrossRef]

131. Dodd, C.V.; Deeds, W.E. Analytical Solutions to Eddy-Current Probe-Coil Problems. J. Appl. Phys. 1968, 39, 2829-2838. [CrossRef]

132. Hillmann, S.; Heuer, H.; Klein, M. Schichtdicken-Charakterisierung dünner, leitfähiger Schichtsysteme mittels Wirbelstromtechnik. In Proceedings of the DGZfP-Jahrestagung, Erfurt, Germany, 10-12 May 2010.

133. Suragus GmbH. EddyCus ${ }^{\circledR}$ TF Lab 4040. Available online: https:/ /www.suragus.com/en/products/thinfilm-characterization/sheet-resistance/eddycus-tf-lab-4040/ (accessed on 29 December 2016).

134. Fiorillo, F. Measurement and Characterization of Magnetic Materials; Elsevier: Amsterdam, The Netherlands, 2004.

135. Hillmann, S.; Klein, M.; Heuer, H. In-line thin film characterization using eddy current techniques. Stud. Appl. Electromagn. Mech. 2011, 35, 330-338.

136. García-Martín, J.; Gómez-Gil, J.; Vázquez-Sánchez, E. Non-destructive techniques based on eddy current testing. Sensors 2011, 11, 2525-2565. [CrossRef] [PubMed]

137. Singh, S.K. Industrial Instrumentation \& Control, 2nd ed.; McGraw-Hill Education: Noida, India, 2003.

138. Rajotte, R.J. Eddy-current method for measuring the electrical conductivity of metals. Rev. Sci. Instrum. 1975, 46, 743-745. [CrossRef]

139. Heuer, H.; Hillmann, S.; Roellig, M.; Schulze, M.H.; Wolter, K.J. Thin film characterization using high frequency eddy current spectroscopy. In Proceedings of the 9th IEEE Conference on Nanotechnology (2009 IEEE-NANO), Genoa, Italy, 26-30 July 2009.

140. Moulder, J.C.; Uzal, E.; Rose, J.H. Thickness and conductivity of metallic layers from eddy current measurements. Rev. Sci. Instrum. 1992, 63, 3455-3465. [CrossRef]

141. Angani, C.S.; Ramos, H.G.; Ribeiro, A.L.; Rocha, T.J.; Prashanth, B. Transient eddy current oscillations method for the inspection of thickness change in stainless steel. Sens. Actuators A Phys. 2015, 233, 217-223. [CrossRef]

142. Qu, Z.; Zhao, Q.; Meng, Y. Improvement of sensitivity of eddy current sensors for nano-scale thickness measurement of Cu films. NDT E Int. 2014, 61, 53-57. [CrossRef]

143. Mehrabad, M.J.; Ehsani, M.H. An Investigation of Eddy Current, Solid Loss, Induced Voltage and Magnetic Torque in Highly Pure Thin Conductors, Using Finite Element Method. Procedia Mater. Sci. 2015, 11, $412-417$. [CrossRef]

(C) 2017 by the authors; licensee MDPI, Basel, Switzerland. This article is an open access article distributed under the terms and conditions of the Creative Commons Attribution (CC-BY) license (http://creativecommons.org/licenses/by/4.0/). 